Secuencia cronológica de las ocupaciones prehispánicas del sector central de la Quebrada de Humahuaca (Jujuy, Argentina)

María Clara Rivolta, Clarisa Otero, Catriel Greco

Relaciones, 46(2), e015, julio-diciembre 2021

ISSN 1852-1479 | https://doi.org/10.24215/18521479e015

https://revistas.unlp.edu.ar/relaciones

ISSN 0325-2221 (versión impresa)

Sociedad Argentina de Antropología (SAA)

Buenos Aires I Argentina

\title{
SECUENCIA CRONOLÓGICA DE LAS OCUPACIONES PREHISPÁNICAS DEL SECTOR CENTRAL DE LA QUEBRADA DE HUMAHUACA (JUJUY, ARGENTINA)
}

\author{
María Clara Rivolta*, Clarisa Otero** y Catriel Greco ${ }^{* * *}$
}

Fecha de recepción: 20 de mayo de 2021

Fecha de aceptación: 3 de octubre de 2021

\section{RESUMEN}

Se propone una nueva secuencia cronológica para el sector central de la Quebrada de Humahuaca (Jujuy, Argentina), estructurada en cinco períodos que dan cuenta de los cambios y continuidades en las poblaciones locales entre los que se destaca la presencia de grupos extrarregionales. Partiendo de la compilación de todos los fechados radiocarbónicos publicados hasta el momento, se analizó el contexto de procedencia, lo que permitió clasificar los datos a partir de la información vinculada con las características arquitectónicas, de emplazamiento y alfarería. Esto permitió examinar las tendencias temporales de los patrones observables utilizando modelación estadística bayesiana y destacar situaciones de contemporaneidad entre fenómenos anteriormente considerados como sucesivos en el tiempo. La propuesta no está estructurada para ofrecer un modelo cerrado, sino más bien para consolidar un esquema de trabajo que parte de hipótesis basadas en datos actualizados y confiables que deberán ser puestas a prueba en futuras investigaciones.

\footnotetext{
* Instituto Interdisciplinario Tilcara, Facultad de Filosofía y Letras, Universidad de Buenos Aires (UBA). Instituto de Investigaciones en Ciencias Sociales y Humanidades (ICSOH), Universidad Nacional de Salta. E-mail: rivoltaclara@gmail.com

** Instituto de Datación y Arqueometría, Consejo Nacional de Investigaciones Científicas y Técnicas. Instituto Interdisciplinario Tilcara, Facultad de Filosofía y Letras, Universidad de Buenos Aires (UBA). E-mail: clarisaotero@yahoo.com.ar

*** Departamento de Geología, Universidad Nacional de San Luis - Consejo Nacional de Investigaciones Científicas y Técnicas. E-mail: catrielgreco@conicet.gov.ar
} 
Relaciones de la Sociedad Argentina de Antropología 46 (2), julio-diciembre 2021: 415-448

Palabras clave: temporalidad-Noroeste argentino-materialidad-procesos prehispánicos - modelos bayesianos

\author{
CHRONOLOGICAL SEQUENCE OF THE PREHISPANIC OCCUPATIONS OF THE \\ CENTRAL SECTOR OF QUEBRADA DE HUMAHUACA (JUJUY, ARGENTINA)
}

\title{
ABSTRACT
}

This work proposes a new chronological sequence for the central sector of Quebrada de Humahuaca (Jujuy, Argentina), structured in five periods that account for the changes and continuities within local populations and the presence of extra-regional groups. Based on a compilation of all radiocarbon dates published to date, the immediate context of origin was analyzed, which allowed classifying the data from the information related to the architectural, settlement pattern and pottery characteristics considering their level of representativeness in the analyzed regional segment. This allowed us to examine the temporal trends of the observable patterns using Bayesian statistical modeling and to highlight contemporaneity situations between phenomena previously considered as successive in time. The structure of this proposal is not meant to offer a closed model, but rather to consolidate a work scheme built upon hypotheses based on updated and reliable data that should be tested in future research.

Keywords: temporality - northwestern Argentina - materiality - pre-Hispanic processes - bayesian modeling

\section{INTRODUCCIÓN}

La formulación de esquemas cronológicos en Arqueología constituye una herramienta valiosa en la medida que permite construir marcos de referencia a partir de los cuales posicionar las sociedades en el pasado. Claramente, las primeras propuestas para el Noroeste argentino tuvieron como objetivo situar diferentes manifestaciones materiales, en particular valiéndose de los estilos cerámicos, en ausencia de otras técnicas de análisis más precisas. En la actualidad, a pesar de contar con diversos métodos radiométricos, la formulación de esquemas cronológicos sigue representando un modo de comprender y contener los desarrollos de las sociedades prehispánicas, entre las que se pueden considerar perspectivas como procesos sucesivos, resaltando cambios, continuidades, asignaciones recortadas temporalmente del contexto material, grados de contemporaneidad entre tradiciones de diferentes regiones, entre otros. Sin embargo, independientemente del posicionamiento teórico que se tome, resulta conveniente considerar que las construcciones cronológicas son herramientas conceptuales por lo que, en la medida que se producen avances en las investigaciones, deben ser reformuladas acorde con los cambios que demanden los nuevos descubrimientos. Los esquemas construidos resultan operativos solo en la medida que exhiban una estructura de carácter dinámico y flexible. En caso contrario, su capacidad explicativa se reduce, convirtiéndose en un armazón rígido inaplicable a sociedades que como norma no reproducen su vida social en formatos estancos ni de manera lineal. Por ello, resulta importante discutir el grado de predictibilidad y el nivel de aplicabilidad que suele esperarse de las cronologías en la medida que la construcción de bloques temporales tiende a presentar contenidos excluyentes en los que no siempre se atiende a posibles continuidades entre un intervalo y otro.

El objetivo de esta contribución es dar a conocer una propuesta cronológica que se ajuste a las nuevas evidencias como resultado de las investigaciones realizadas en el sector central de la Quebrada de Humahuaca. Dicho sector está delimitado por dos quebradas tributarias, al norte por 
la quebrada de Yacoraite y al sur por la de Purmamarca (figura 1). Representa el sector donde se encuentra el mayor número de sitios arqueológicos estudiados en profundidad y que cuentan con contextos de asociación precisos por lo cual los fechados brindan un alto grado de confiabilidad.

Esta propuesta se sustenta en avances recientes realizados en torno a diferentes problemáticas, entre las que se consideraron dataciones radiocarbónicas, excavaciones, estudios de colecciones, análisis arqueométricos y la reinterpretación de evidencias a partir de enfoques renovados. Si bien, anteriormente realizamos otras contribuciones en torno a la cronología (Otero y Rivolta 2015; Greco y Otero 2016; Rivolta et al. 2017) en este caso se suman una serie de perspectivas diferentes.
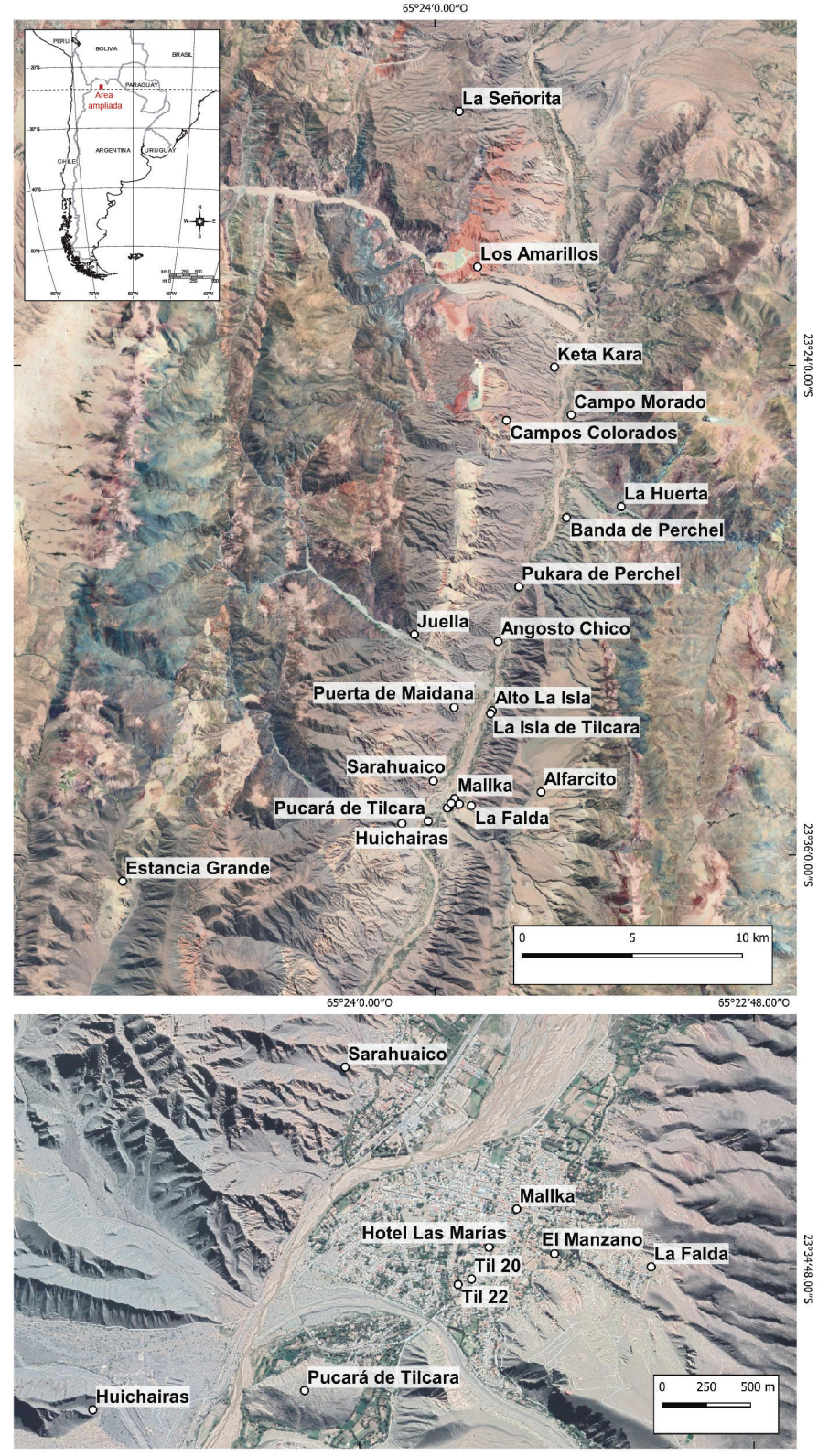

Figura 1. Mapa del sector central de la Quebrada de Humahuaca con la ubicación de los sitios arqueológicos indicados en el texto 
Principalmente, se incluyen dataciones radiocarbónicas considerando las evidencias disponibles hasta la fecha aplicando estadística bayesiana, a fin de lograr un modelo actualizado y que se ajuste a los avances recientes en el campo de la disciplina. Asimismo, se amplió la perspectiva para incluir los desarrollos posteriores al siglo XIV, es decir, no solo los que comprenden a la ocupación incaica, sino también a su desenlace e inicios de la Colonia española, a fin de generar un marco explicativo abarcativo en una propuesta unificada. Finalmente, se construyeron períodos en los que se discuten las evidencias y se plantean hipótesis de trabajo que permitan ahondar y comprender los procesos sociales que tuvieron lugar en el sector bajo estudio interpelando los modelos tradicionales.

\section{LOS DESARROLLOS CRONOLÓGICOS PREVIOS}

A lo largo del tiempo, a partir de información provista por colecciones e investigaciones, se elaboraron distintas propuestas vinculadas a esquemas cronológicos diacrónicos a fin de comprender la dinámica de las sociedades del Noroeste argentino. Si consideramos la época en la que fueron realizadas, es comprensible que no estuvieran refrendadas por resultados radiocarbónicos que permitieran situar de manera precisa a los contextos materiales, al tiempo que las evidencias eran recuperadas aplicando técnicas que actualmente se reconoce que presentan limitaciones metodológicas. Una de las primeras contribuciones basadas en el trabajo sistemático de revisión de colecciones de sitios arqueológicos para el Noroeste argentino fue realizada por Bennett y colaboradores (1948). La metodología desarrollada consistió en segmentar el Noroeste en tres regiones: Norte, Centro y Sur, dando lugar a la conformación de períodos basados en el estudio de colecciones, lo que derivó en la formulación de estilos cerámicos específicos para cada una de las regiones identificadas.

Desde esta perspectiva, la Quebrada de Humahuaca fue ubicada en el segmento Norte y organizada a partir del reconocimiento de cuatro períodos denominados: Temprano, Medio, Tardío e Inca, asociados a tres culturas: Media, Humahuaca e Inca. Asimismo, el cuadro cronológico confeccionado contenía información sobre estilos cerámicos, reconociendo los siguientes: Isla Polícromo, Alfarcito Polícromo, Tilcara negro sobre rojo, Hornillos negro sobre rojo, Angosto chico inciso, Poma negro sobre rojo, Cuzco Polícromo, Complejo Puna y Complejo Iruya (Bennett et al. 1948). Este cuadro constituyó el punto de partida para que, con posterioridad, González (1955) generara otras secuencias temporales que fueron modificándose en la medida que se realizaron avances en las investigaciones. De este modo, su secuencia maestra desarrollada para el valle de Hualfín en Catamarca (González 1955) fue revisada y transformada hasta lograr un esquema abarcativo para todo el Noroeste argentino. Es así que a partir del enfoque sobre culturas agroalfareras define los siguientes intervalos: Período Temprano (primeras culturas hasta el 650 d.C.), Medio (650-850 d.C.), Tardío (850-1480 d.C.), Inca (1480-1536 d.C.), Hispano Indígena (1536 d.C.) y Colonial (1640 d.C.) (González y Pérez 1972). La finalidad principal en la elaboración de esta periodificación se centró en comprender el proceso histórico en el Noroeste argentino y, a su vez, contar con herramientas para relacionar dichos procesos con los acontecidos en general en el área centro-sur Andina. En cuanto al alcance que tuvo este esquema para la Quebrada de Humahuaca, los autores reconocieron la escasa evidencia con la que se contaba al momento de elaborarla, particularmente para el Período Temprano representado por el sitio Estancia Grande, trabajado por Salas (1948). El Período Medio correspondió a las evidencias que fueron registradas para sitios como La Isla de Tilcara y Alfarcito, en tanto el Período Tardío se encontraba reflejado en sitios como Pucará de Tilcara, Yacoraite, Hornillos y Juella. Para el momento incaico, los sitios mejor representados fueron el Pucará de Tilcara y La Huerta. A pesar de contar con este cúmulo de evidencias, la ausencia de dataciones radiocarbónicas dificultó de alguna manera la aplicación 
de este esquema en toda la Quebrada de Humahuaca. A su vez, en la medida que se fueron recopilando más resultados radiocarbónicos, comenzaron a surgir problemas de adecuación entre los intervalos construidos y los nuevos contextos arqueológicos relevados.

A partir de la década de 1980, fue posible ampliar progresivamente el número de fechados obtenidos para la Quebrada de Humahuaca, debido a que las investigaciones incorporaron nuevos sitios de estudio y problemáticas. Desde entonces, se construyeron diferentes esquemas que, en ocasiones, recreaban el primer marco cronológico propuesto por González y Pérez (1972). Entre las diferentes propuestas se cuenta con la de Raffino (1991), quien construye un cuadro general abarcativo tomando como escala de aplicación al Noroeste argentino, iniciando la secuencia con el Período Formativo, segmentado en Inferior (500 a.C.-400 d.C.) y Superior (400 d.C.-900 d.C.); Desarrollos Regionales (900 d.C.-1471 d.C.); Horizonte Inka (1471 d.C.-1532 d.C.) y Período Hispano Indígena (1535 d.C.-1660 d.C.).

Más recientemente, otros esquemas cronológicos se centraron particularmente en la Quebrada de Humahuaca (Nielsen 1997, 2001). Estas propuestas fueron elaboradas a partir de una mayor cantidad de evidencias tanto radiocarbónicas como contextuales, generando un desarrollo en fases (Nielsen 1997). En una contribución posterior, Nielsen (2001) elabora otro modelo en parte sostenido con referencias al previo, pero reconociendo los siguientes períodos: Formativo (final) al que se integra la fase Vizcarra; Desarrollos Regionales I con las fases Calete y Muyuna; Desarrollos Regionales II que incorpora las fases Sarahuaico y Pukara; Inca e Hispano Indígena con las fases homónimas (Nielsen 2001). La propuesta más reciente de este autor (Nielsen 2007) organiza las evidencias arqueológicas utilizando "componentes cerámicos" como unidad conceptual, a fin de evaluar la situación cronológica y sistematizar la materialidad en cuatro grandes conjuntos: Alfarcito Antiguo, Isla/Alfarcito, Humahuaca e Inka. Retomamos de ese trabajo la idea de organizar los datos disponibles sobre la base de la materialidad observable y evaluar su cronología con estadística bayesiana, siendo un antecedente directo para esta metodología a nivel regional.

Posteriormente, y a escala más específica, Otero y Rivolta (2015) elaboraron un esquema de intervalos para la planta urbana de Tilcara en el que se identificaron ocupaciones: del primer milenio de la era, siglos XI a XIV, XIII-XIV al XV, XV a XVI, siglo XVI e intervalo del primer momento histórico. La cronología se generó sumando a resultados previos los contextos materiales y fechados de investigaciones recientes, que fueron confrontados con los esquemas de cronología clásicos, permitiendo de este modo evidenciar la dificultad inherente de ubicar el momento Isla en el Período Medio, tal como fuera señalado en el esquema de González y Pérez (1972). Otras de las dificultades que remarcan las autoras de este esquema es la amplitud temporal propuesta para el Formativo o Período Temprano en Tilcara, sugiriendo una mayor antigüedad que la que habían considerado González y Pérez (1972). Claramente la falta de adecuación entre esta cronología clásica y la reciente, que partió tanto de los resultados radiocarbónicos como de las investigaciones realizadas en el sector central de la Quebrada de Humahuaca, dieron cuenta de la necesidad de efectuar ajustes mayores para analizar las problemáticas que se iban originando. En una contribución posterior y mediante la aplicación de estadística bayesiana se efectuó un planteo reconociendo particularidades de la cronología en el sector central de la Quebrada, a partir de la identificación de momentos designados como: Formativo, Humahuaca Temprano e Isla, para lo cual se combinaron evidencias materiales y arquitectónicas asociadas a los resultados radiocarbónicos (Rivolta et al. 2017). En este texto además se discutió la problemática Isla planteando como hipótesis el desplazamiento de grupos altiplánicos hacia la Quebrada de Humahuaca, sin embargo, no se incluyeron eventos posteriores al siglo XV d.C. Es a partir de la presente contribución que se toman en cuenta los desarrollos completos para el sector central, desde la reflexión crítica centrada en la producción de los propios autores de este trabajo. 


\section{METODOLOGÍA}

El análisis cronológico parte de una revisión bibliográfica exhaustiva a fin de generar una base de datos de fechados radiocarbónicos para el área de estudio. En total se cuenta con 109 dataciones que fueron realizadas entre los años 1967 y 2019 (tabla 1). Dejamos de lado aquellas que fueron procesadas antes de 1980, es decir un total de dos dataciones, ya que podrían tener distintos estándares de medición y sería necesario corregirlas (Carbonari et al. 2011). Del mismo modo, se descartaron seis mediciones con un error de 100 años o más ya que agregaban demasiada imprecisión al análisis estadístico. Es por ello que finalmente, la muestra analizada estadísticamente se compone de 101 fechados. En cada caso revisamos la información disponible sobre los contextos, los materiales directamente asociados y respetamos la interpretación de los autores con respecto a la cronología de los sitios y la confiabilidad de los resultados.

Para esta propuesta adoptamos un enfoque cronológico bayesiano, que implica asignar los fechados a grupos sobre la base de criterios arqueológicos y establecer un orden entre ellos en caso de que hubiera información suficiente. Utilizamos un modelo de fases uniformes y superpuestas (Buck et al. 1996; Bronk Ramsey 2009) para evaluar siete grupos de fechados de manera independiente. De este modo, entendemos que aquellas categorías cronológicas tradicionales (o surgidas desde otros marcos conceptuales), como Formativo, Isla o Tardío pueden reconceptualizarse como procesos, que no necesariamente son consecutivos, sino posiblemente contemporáneos.

Tabla 1. Base de datos de fechados radiocarbónicos del área de estudio

\begin{tabular}{|c|c|c|c|c|}
\hline$\#$ & Cod. Lab. & Sitio & Años C14 AP & Referencia \\
\hline \multicolumn{5}{|c|}{ A) Ocupaciones en Aldeas } \\
\hline $1-*$ & LP 442 & Alfarcito & $2020 \pm 100$ & Tarragó y Albeck 1997 \\
\hline $2-$ & LP 586 & Alfarcito & $1970 \pm 70$ & Tarragó y Albeck 1997 \\
\hline $3-$ & LP 539 & Estancia Grande & $1900 \pm 60$ & Palma y Olivera 1992-93 \\
\hline $4-$ & LP 310 & Estancia Grande & $1510 \pm 70$ & Palma y Olivera 1992-93 \\
\hline $5-$ & B132947 & Til 20 & $1450 \pm 40$ & Mendonca et al. 2002 \\
\hline $7-$ & LP 346 & Til 22 & $1190 \pm 90$ & Rivolta 1996a \\
\hline 9 - & B 80704 & Til 22 & $1160 \pm 80$ & Tarragó y Albeck 1997 \\
\hline $12-*$ & LP 349 & Til 22 & $1025 \pm 140$ & Rivolta 1996a \\
\hline $14-$ & LP 551 & Estancia Grande & $970 \pm 50$ & Palma y Olivera 1992-93 \\
\hline $16-$ & LP 336 & Til 22 & $940 \pm 60$ & Rivolta 1996a \\
\hline $17-$ & LP 988 & Malka & $940 \pm 60$ & Nielsen 2001 \\
\hline \multicolumn{5}{|c|}{ B) Ocupaciones en Terrazas } \\
\hline $8-$ & AA16236 & Banda de Perchel & $1163 \pm 49$ & Rivolta 1997 \\
\hline $24-$ & ISGS- 3249 & Alto de La Isla & $870 \pm 70$ & Rivolta 2000 \\
\hline $28-$ & ISGS- 4415 & Banda de Perchel & $850 \pm 70$ & Rivolta 2003 \\
\hline $30-$ & A9605 & Quebrada del Cementerio & $835 \pm 40$ & Nielsen et al. 2003-05 \\
\hline $31-$ & ISGS- 4416 & Banda de Perchel & $830 \pm 70$ & Rivolta 2003 \\
\hline $32-$ & ISGS- 3250 & Puerta de Maidana & $810 \pm 70$ & Nielsen y Rivolta 1997 \\
\hline $35-$ & ISGS- 4417 & Alto de La Isla & $790 \pm 70$ & Rivolta 2003 \\
\hline $40-$ & AA88374 & Pukara de Perchel & $737 \pm 29$ & Scaro y Sica 2015 \\
\hline $42-$ & ISGS- 2521 & Sarahuaico & $730 \pm 70$ & Rivolta 1996b \\
\hline $43-$ & ISGS-2754 & Sarahuaico & $710 \pm 70$ & Rivolta 1996b \\
\hline
\end{tabular}


María CLARA Rivolta y otros - SECUENCIA CRONOLÓGiCA DE LAS OCUPACIONES PREHISPÁNICAS DEL SECTOR ...

(Tabla 1. Continuación)

\begin{tabular}{|c|c|c|c|c|}
\hline \# & Cod. Lab. & Sitio & Años C14 AP & Referencia \\
\hline $44-$ & ISGS-2522 & Sarahuaico & $690 \pm 80$ & Rivolta $1996 b$ \\
\hline $50-$ & ISGS- 3251 & Puerta de Maidana & $660 \pm 70$ & Nielsen y Rivolta 1997 \\
\hline $53-$ & AA13669 & La Señorita & $648 \pm 49$ & Nielsen 1996 \\
\hline $55-$ & AA16234 & Campos Colorados & $642 \pm 49$ & Nielsen 1996 \\
\hline $61-$ & A9606 & Quebrada del Cementerio & $630 \pm 35$ & Nielsen et al. 2003-05 \\
\hline $67-$ & AA16235 & Campos Colorados & $600 \pm 49$ & Nielsen 1996 \\
\hline $86-$ & LP 998 & Banda de Perchel & $510 \pm 40$ & Rivolta 2003 \\
\hline $97-$ & LP 1990 & Angosto Chico & $450 \pm 60$ & Rivolta et al. $2010 \mathrm{~b}$ \\
\hline \multicolumn{5}{|c|}{ C) Ocupaciones en Semiconglomerados } \\
\hline $23-$ & AA 13667 & Keta Kara & $889 \pm 57$ & Nielsen 1997 \\
\hline $25-$ & LP 2974 & Hotel Las Marías & $870 \pm 60$ & Otero y Rivolta 2015 \\
\hline $26-$ & AA-89441 & Keta Kara & $864 \pm 45$ & Rivolta 2013 \\
\hline $29-$ & AA98249 & La Isla de Tilcara & $838 \pm 46$ & Cocilovo et al. 2019 \\
\hline $47-$ & LP-2968 & Keta Kara & $670 \pm 40$ & Rivolta 2013 \\
\hline $59-$ & LP-2964 & Keta Kara & $630 \pm 40$ & Rivolta 2013 \\
\hline $71-$ & LP1919 & El Manzano & $570 \pm 90$ & Otero y Rivolta 2015 \\
\hline $76-$ & LP 2019 & El Manzano & $560 \pm 70$ & Otero y Rivolta 2015 \\
\hline
\end{tabular}

D) Ocupaciones en Conglomerados

\begin{tabular}{|c|c|c|c|c|}
\hline \multicolumn{5}{|c|}{ D1 Basurales } \\
\hline $10-$ & LP 466 & Pucará de Tilcara & $1160 \pm 80$ & Tarragó y Albeck 1997 \\
\hline $11-$ & LP 165 & La Huerta & $1150 \pm 80$ & Raffino y Alvis 1993 \\
\hline $13-$ & LP 531 & Pucará de Tilcara & $1020 \pm 80$ & Tarragó y Albeck 1997 \\
\hline $15-$ & LP 486 & Pucará de Tilcara & $950 \pm 80$ & Tarragó y Albeck 1997 \\
\hline $18-$ & LP 532 & Pucará de Tilcara & $930 \pm 70$ & Tarragó y Albeck 1997 \\
\hline $22-$ & AA 13670 & Los Amarillos & $891 \pm 50$ & Nielsen 1996 \\
\hline $27-$ & LP 485 & Pucará de Tilcara & $860 \pm 90$ & Tarragó y Albeck 1997 \\
\hline $34-$ & LP 2960 & Pucará de Tilcara & $800 \pm 50$ & Greco y Otero 2016 \\
\hline $37-$ & LP 544 & Pucará de Tilcara & $770 \pm 70$ & Tarragó y Albeck 1997 \\
\hline $49-$ & UCIAMS-234326 & Pucará de Tilcara & $665 \pm 15$ & Otero et al. $2021 \mathrm{~b}$ \\
\hline $54-$ & UCIAMS-226709 & Pucará de Tilcara & $645 \pm 15$ & Otero et al. $2021 \mathrm{~b}$ \\
\hline $66-$ & LP 546 & Pucará de Tilcara & $610 \pm 60$ & Tarragó y Albeck 1997 \\
\hline $72-$ & LP 2965 & Pucará de Tilcara & $570 \pm 50$ & Greco y Otero 2016 \\
\hline $84-$ & LP 2967 & Pucará de Tilcara & $520 \pm 40$ & Greco y Otero 2016 \\
\hline \multicolumn{5}{|c|}{ D2 contextos sin evidencia inca } \\
\hline $6-*$ & IVIC 186 & Juella & $1320 \pm 30$ & Cigliano 1967 \\
\hline $19-$ & LP 659 & Los Amarillos & $920 \pm 50$ & Nielsen 1996 \\
\hline $20-$ & AA 12137 & Los Amarillos & $915 \pm 85$ & Nielsen 1996 \\
\hline $21-$ & LP 536 & Pucará de Tilcara & $910 \pm 70$ & Tarragó y Albeck 1997 \\
\hline $33-$ & LP 247 & Pucará de Tilcara & $800 \pm 50$ & Tarragó y Albeck 1997 \\
\hline $36-$ & LP 669 & Los Amarillos & $780 \pm 70$ & Nielsen 2007 \\
\hline $38-*$ & LP 389 & La Huerta & $740 \pm 110$ & Palma 1998 \\
\hline $39-$ & LP 3340 & Pucará de Tilcara & $740 \pm 50$ & Otero et al. 2017 \\
\hline $41-$ & AA88361 & Huichairas & $733 \pm 33$ & Mercolli et al. 2014 \\
\hline
\end{tabular}


Relaciones de la Sociedad Argentina de Antropología 46 (2), julio-diciembre 2021: 415-448

(Tabla 1. Continuación)

\begin{tabular}{|c|c|c|c|c|}
\hline$\#$ & Cod. Lab. & Sitio & Años C14 AP & Referencia \\
\hline $45-$ & LP 335 & La Huerta & $680 \pm 90$ & Palma 1998 \\
\hline $46-$ & UGAMS 03256 & Campo Morado & $680 \pm 20$ & Fernández do Río 2009 \\
\hline $48-$ & UGAMS 03257 & Campo Morado & $670 \pm 25$ & Fernández do Río 2009 \\
\hline $51-$ & LP 700 & La Huerta & $660 \pm 40$ & Palma 1998 \\
\hline $52-$ & AA16237 & Juella & $655 \pm 49$ & Nielsen 1996 \\
\hline $56-$ & UGAMS 03258 & Campo Morado & $640 \pm 25$ & Fernández do Río 2009 \\
\hline $57-*$ & A7733 & Juella & $635 \pm 140$ & Nielsen 1996 \\
\hline $58-$ & AA89445 & Pucará de Tilcara & $635 \pm 52$ & Otero et al: 2017 \\
\hline $60-$ & A 9602 & Los Amarillos & $630 \pm 45$ & \begin{tabular}{|l|} 
Nielsen 2007 \\
\end{tabular} \\
\hline $62-*$ & M1639 & Juella & $630 \pm 120$ & Cigliano 1967 \\
\hline $63-$ & AA88360 & Huichairas & $626 \pm 45$ & Mercolli et al. 2014 \\
\hline $64-$ & AA 16239 & Los Amarillos & $620 \pm 49$ & Nielsen 1996 \\
\hline $65-$ & LP 3329 & Pucará de Tilcara & $620 \pm 50$ & Greco y Otero 2016 \\
\hline $68-$ & AA 12135 & Los Amarillos & $590 \pm 55$ & Nielsen 1996 \\
\hline $69-*$ & GRN540 & Juella & $590 \pm 30$ & Pelissero 1969 \\
\hline $70-$ & AC 0963 & La Huerta & $580 \pm 80$ & Palma 1998 \\
\hline $73-$ & LP 1868 & Campo Morado & $570 \pm 70$ & Fernández do Río 2009 \\
\hline $77-$ & LP 1387 & Los Amarillos & $560 \pm 60$ & Nielsen 2007 \\
\hline $78-$ & AC 1069 & La Huerta & $540 \pm 90$ & Palma 1998 \\
\hline $79-$ & LP 1399 & Los Amarillos & $540 \pm 50$ & Nielsen 2007 \\
\hline $80-$ & LP 1397 & Los Amarillos & $530 \pm 60$ & Nielsen 2007 \\
\hline $89-$ & A 9604 & Los Amarillos & $495 \pm 40$ & Nielsen 2007 \\
\hline $90-$ & AA85659 & Juella & $486 \pm 42$ & Leibowicz 2013 \\
\hline $93-$ & AA85658 & Juella & $454 \pm 42$ & Leibowicz 2013 \\
\hline $94-$ & LP 2544 & Juella & $450 \pm 60$ & Leibowicz 2013 \\
\hline $95-$ & LP 2556 & Juella & $450 \pm 50$ & Leibowicz 2013 \\
\hline \multicolumn{5}{|c|}{ D3 contextos con evidencia inca } \\
\hline $74-$ & AA89444 & Pucará de Tilcara & $566 \pm 52$ & Greco y Otero 2016 \\
\hline $75-$ & AA88341 & Pucará de Tilcara & $561 \pm 42$ & Otero et al. 2017 \\
\hline $81-$ & AA88338 & Pucará de Tilcara & $527 \pm 47$ & Greco y Otero 2016 \\
\hline $82-$ & AA88339 & Pucará de Tilcara & $523 \pm 47$ & Greco y Otero 2016 \\
\hline $83-$ & A 9603 & Los Amarillos & $520 \pm 40$ & $\begin{array}{l}\text { Nielsen 2007; Nielsen y } \\
\text { Walker } 1999\end{array}$ \\
\hline $85-$ & AA88340 & Pucará de Tilcara & $512 \pm 41$ & Otero et al. 2017 \\
\hline $87-$ & AA88342 & Pucará de Tilcara & $510 \pm 46$ & Otero et al. 2017 \\
\hline $88-$ & A 9600 & Los Amarillos & $505 \pm 50$ & Nielsen 2007 \\
\hline $91-*$ & AC 0960 & La Huerta & $480 \pm 100$ & Palma 1998 \\
\hline $92-$ & LP 2467 & Pucará de Tilcara & $470 \pm 50$ & Otero et al. 2017 \\
\hline $100-$ & LP 2240 & Pucará de Tilcara & $450 \pm 40$ & Otero et al. 2017 \\
\hline $96-$ & AA 12136 & Los Amarillos & $450 \pm 50$ & $\begin{array}{l}\text { Nielsen 2007; Nielsen y } \\
\text { Walker } 1999\end{array}$ \\
\hline $98-$ & LP 2191 & Pucará de Tilcara & $450 \pm 60$ & Otero et al. 2017 \\
\hline 99 - & LP 2231 & Pucará de Tilcara & $450 \pm 50$ & Otero et al. 2017 \\
\hline $101-$ & LP 2448 & Pucará de Tilcara & $440 \pm 40$ & Greco y Otero 2016 \\
\hline
\end{tabular}


María CLARA Rivolta y otros - SECUENCIA CRONOLÓGiCA DE LAS OCUPACIONES PREHISPÁNICAS DEL SECTOR ...

(Tabla 1. Continuación)

\begin{tabular}{|c|l|l|l|l|}
\hline$\#$ & \multicolumn{1}{|c|}{ Cod. Lab. } & \multicolumn{1}{c|}{ Sitio } & Años C14 AP & \multicolumn{1}{c|}{ Referencia } \\
\hline 102 - & LP 2433 & Pucará de Tilcara & $380 \pm 50$ & Greco y Otero 2016 \\
\hline 107 - & LP 1896 & Campo Morado & $350 \pm 60$ & Fernández do Río 2009 \\
\hline 108 - & A 9601 & Los Amarillos & $320 \pm 50$ & $\begin{array}{l}\text { Nielsen 2007; Nielsen y } \\
\text { Walker 1999 }\end{array}$ \\
\hline 109 - & LP 1838 & Campo Morado & $280 \pm 50$ & Fernández do Río 2009 \\
\hline \multicolumn{5}{|c|}{ D4 contextos con evidencia colonial } \\
\hline 103 - & Beta 153720 & La Falda & $380 \pm 40$ & Arrieta et al. 2016 \\
\hline $104-$ & D-AMS 028343 & Pucará de Tilcara & $376 \pm 27$ & López Geronazzo et al. 2019 \\
\hline 105 - & Beta 153721 & La Falda & $370 \pm 40$ & Arrieta et al. 2016 \\
\hline 106 - & D-AMS 028344 & Pucará de Tilcara & $358 \pm 24$ & López Geronazzo et al. 2019 \\
\hline
\end{tabular}

* Indica aquellos que no se toman en cuenta por haber sido realizados antes de 1980 o por tener un error de 100 o más años. La numeración es por la antigüedad absoluta.

El área de estudio se encuentra en el límite sur estimado para la zona de convergencia intertropical (ZCIT) (Hogg et al. 2020) y de la influencia del Monzón Sudamericano, con una potencial mezcla de masas de aire de los hemisferios norte y sur (Marsh et al. 2018). Por lo tanto, siguiendo las recomendaciones de ambos trabajos utilizaremos una curva de calibración mixta entre IntCal20 (Reimer et al. 2020) y SHCal20 (Hogg et al. 2020). Esto podría generar ciertas discrepancias con resultados previos, aunque las variaciones entre usar la curva mixta o solo ShCal20 no son mayores a veinte años para cada edad calibrada (Nesbitt et al. 2020). El análisis estadístico se realizó con el software OxCal v4.3 (Bronk Ramsey 2009) y los resultados se representan con gráficos KDE (Kernel Density Estimation) que muestran una conjunción de probabilidades modeladas de todos los fechados individuales y se utilizan para representar la duración de los procesos datados a nivel regional. La ventaja con respecto a otras técnicas de suma de probabilidades es que los gráficos KDE reducen el ruido debido al número limitado de muestras, al proceso de calibración y a la incertidumbre excesiva de algunos fechados (Bronk Ramsey 2017). Asimismo, para cada grupo se calcularon los parámetros de límite cronológico inicial y final, que utilizaremos para plantear nuestra propuesta cronológica.

Para clasificar los fechados en grupos excluyentes tomamos en cuenta la combinación de evidencias surgidas recientemente, sumada a reinterpretaciones vinculadas con la dinámica sociocultural en el sector central de la Quebrada de Humahuaca. Entre los criterios se han considerado variables tales como: contexto material, poniendo particular énfasis en los conjuntos alfareros; emplazamiento y disposición de los sitios en el paisaje; tipo de organización interna y características arquitectónicas. La selección de la alfarería dentro del conjunto de la materialidad se debe a que constituye un elemento presente en la totalidad de los sitios relevados y refleja un volumen de información comparativamente mayor que otros elementos del registro. Los demás componentes de la materialidad pueden estar presentes en ocasiones y de manera diferencial o directamente encontrarse ausentes de los registros con lo cual resulta complejo abordarlos de manera comparativa. Del mismo modo, la localización de los sitios en el paisaje representa una variable que, por lo común, se manifiesta, al igual que los rasgos arquitectónicos en gran parte de los poblados, aún en caso de que estén constituidos por un segmento de la totalidad.

En cuanto a la organización interna, se consideró el modo en que se ordenan los diferentes espacios (caminos, plazas, recintos, etc.) en el interior de los sitios. No obstante, uno de los elementos que condicionaría la interpretación es que los sitios que convalidan el esquema no siempre corresponden a poblados. En este sentido, la información utilizada remite no solo al registro de 
asentamientos para los que se cuenta con sus trazas distinguidas por entero, sino que también se incluyen unidades arquitectónicas aisladas, espacios de inhumación, es decir evidencias parciales con diferentes grados de asociación al contexto material.

De acuerdo con lo señalado, y luego de analizar distintas opciones, las evidencias fueron agrupadas en torno a las siguientes denominaciones: A) ocupación en aldeas, B) ocupación en terrazas, C) ocupación en semiconglomerados y D) ocupación en conglomerados (figura 7). Estas categorías se generaron a fin de dar cuenta del registro material, las particularidades arquitectónicas y de emplazamiento para los diferentes sitios analizados; de manera sumatoria incorporaron evidencias de carácter descriptivo útiles para postular nuevas interpretaciones. Con respecto a los fechados radiocarbónicos, consideramos que sería ideal referir los resultados al sector de procedencia y al contexto asociado, y no atribuirlo a la totalidad del sitio de donde se obtuvo la muestra (tabla 2). Dado que, por el momento, no es posible avanzar con una propuesta de estas características, se implementó una estrategia metodológica particular para el caso de los conglomerados debido a que la gran cantidad de contextos excavados permite una clasificación con mayor detalle, distinguiendo los siguientes subgrupos:

D1) basurales

D2) contextos sin evidencia inca

D3) contextos con evidencia inca

D4) contextos con evidencia colonial

Tabla 2. Estimaciones del inicio de final de cada grupo de fechados.

Valores redondeados cada 10 años

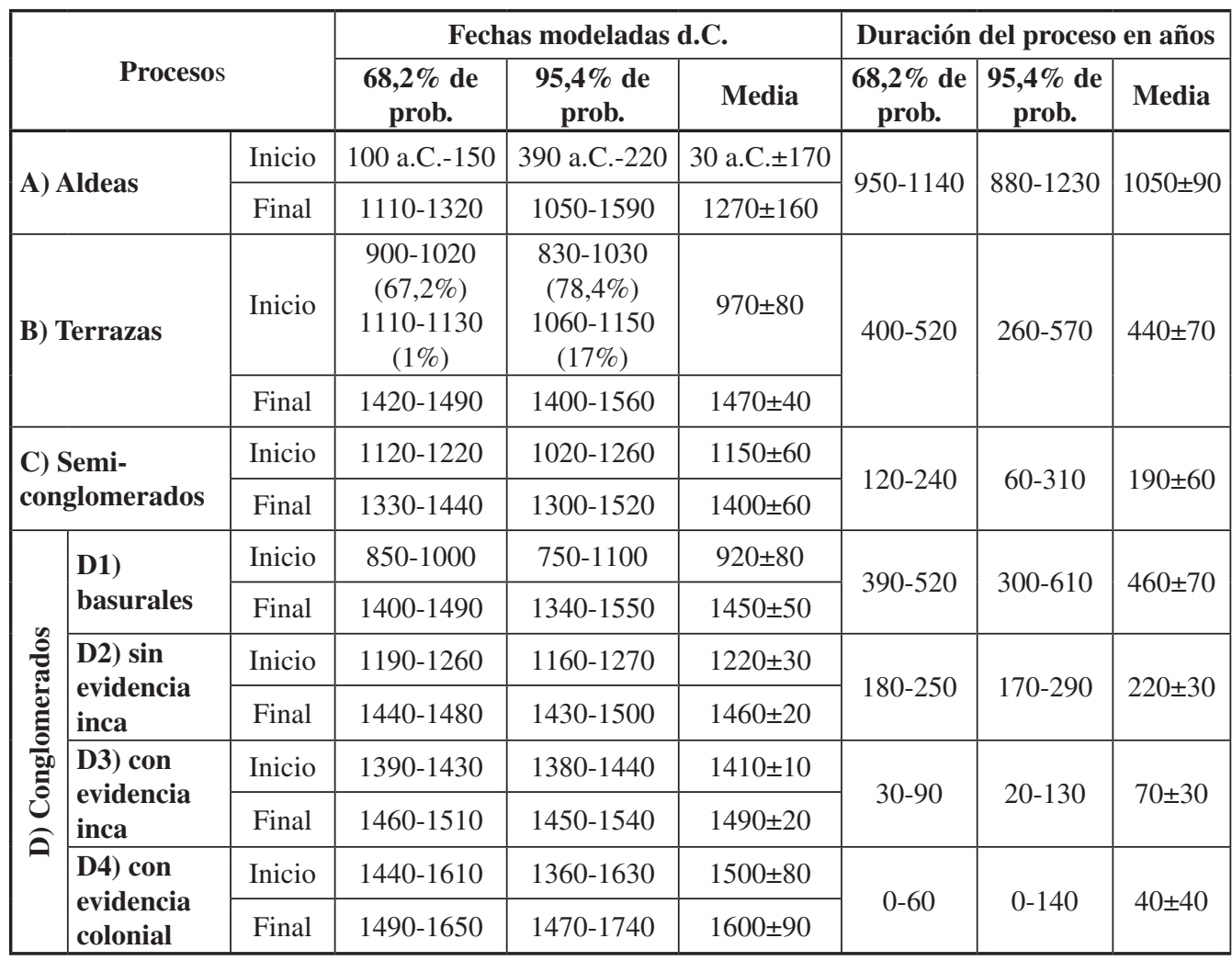


María CLARA Rivolta y otros - SECUENCIA CRONOLÓGiCA DE LAS OCUPACIONES PREHISPÁNICAS DEL SECTOR ...

\section{CARACTERÍSTICAS DE LAS OCUPACIONES}

\section{Ocupación en aldeas}

En lo que comprende al sector central de la Quebrada de Humahuaca, las evidencias de las primeras sociedades sedentarias son escasas y se concentran en dos entornos diferentes, en el fondo de valle (correspondiente a la planta urbana de Tilcara) por un lado y en las quebradas altas, por el otro.

Para el caso de Tilcara, la gran mayoría de los sitios formaron parte de rescates arqueológicos que brindaron información relevante, entre las que se cuentan estructuras arquitectónicas representadas por segmentos de muros (posiblemente constitutivos de recintos habitacionales) así como también contextos de inhumación del tipo cistas y agrupamientos de tumbas. El uso del término aldea está directamente vinculado con el concepto que en general se asocia a ocupaciones del primer milenio de la era, de carácter sedentario cuyos modelos arquitectónicos resultan heterogéneos con patrones de patio central y recintos circulares adosados dispersos entre áreas de cultivo, como sería el caso de Tafí (Berberián y Nielsen 1988; Oliszewski 2017) hasta agrupamientos concentrados, tal es el caso de la Aldea Piedra Negra, con 450 hectáreas cubiertas de estructuras residenciales (Delfino et al. 2015).

Claramente, y hasta el momento, las evidencias no permiten constatar el grado de organización existente para esta instancia en la Quebrada de Humahuaca ya que la posibilidad de identificar contextos completos resulta sumamente dificultosa dado que sobre estos mismos espacios se asentaron los poblados modernos.

Por otra parte, los sitios localizados en quebradas altas son Alfarcito (Debenedetti 1918a; Madrazo 1969a; Zaburlín et al. 1996; Tarragó y Albeck 1997) y Estancia Grande (Salas 1948; Palma y Olivera 1992-93; Olivera y Palma 1997). Ambos marcan una diferencia en términos de emplazamiento con los anteriormente mencionados debido a que se trata de poblados extensos con estructuras complejas. Esto implica que posiblemente estuvieron ocupados durante siglos, marcando una trayectoria vinculada a diversos períodos y no únicamente al grupo de aldeas. Para el caso de Alfarcito, si bien las dataciones corresponden a uno de los trabajos de investigación en el que se intervinieron un perfil y una terraza (Zaburlín et al. 1996), las referencias del sitio lo definen como de gran extensión en el que se distinguen espacios de cultivo con recintos habitacionales dispersos (Debenedetti 1918a; Madrazo 1969a). Del mismo modo, el emplazamiento de Estancia Grande comprende sectores diversificados con características disímiles entre los que se reconocieron contextos materiales y fechados representativos de este momento (Palma y Olivera 1992-93; Olivera y Palma 1997).

En cuanto al conjunto de restos materiales se cuenta con cerámica, en general fragmentada, puntas de proyectil, adornos elaborados en metal y cuentas de collar, entre los más destacados. Con particular referencia a la cerámica, son frecuentes los estilos monocromos pulidos y alisados en tonalidades grises, negras, marrones y ante, mientras que los diseños pintados se restringen al negro sobre rojo con diseño de líneas paralelas y quebradas en vasos y escudillas altas (Rivolta y Albeck 1992; Olivera y Palma 1997; Tarragó y Albeck 1997; Juárez et al. 2020). En cerámica también se realizaron modelados zoomorfos y pipas. En cuanto a los tipos ordinarios resultan mayoritarios en todas las colecciones y forman parte, entre otros, de las grandes ollas tubulares de aproximadamente $1 \mathrm{~m}$ de alto, cuyas funciones alternaron entre el almacenaje y entierros esporádicos de párvulos. Cabe mencionar que el estilo pintado negro sobre rojo no está presente en los contextos tempranos de Alfarcito ni de Estancia Grande (Zaburlín et al. 1996, Olivera y Palma 1997).

Los sitios que representan este grupo y que cuentan con fechados por radiocarbono son: Til. 20 (Mendonça et al. 1991; Barboza et al. 2003), Til.22 (Rivolta y Albeck 1992; Rivolta 1996), 
Estancia Grande (Salas 1948; Palma y Olivera 1992-93; Olivera y Palma 1997), Alfarcito (Zaburlín et al. 1996; Tarragó y Albeck 1997), Malka (Nielsen 1997; Juárez et al. 2020). Incluimos también como parte de este grupo los sitios que comparten las características previamente mencionadas, pero que no cuentan con dataciones absolutas: Til.23 (Aleksandrowicz 1987a), El Antigal (Madrazo 1968), Intiwayna (Rivolta et al. 2010a) y Flores I (Seldes 2006). En el caso del rescate realizado en Calle Belgrano (Tarragó y Albeck 1997), si bien cuenta con fechado radiocarbónico, el resultado obtenido estaría fuera del rango del grupo de aldeas. Es posible que la muestra utilizada para esta datación sea de un evento intrusivo.

\section{Ocupación en terrazas}

Está conformado por poblados que presentan la particularidad de redefinir el uso de las laderas como espacios habitacionales partiendo de una resolución similar a la utilizada para sectores agrícolas. Cada uno de los escalones constituye un componente desde la perspectiva de la unidad doméstica, en el que el muro perimetral bordea al sector aterrazado. Presentan subdivisiones internas y muros de contención por fuera del perímetro principal, posiblemente para minimizar los efectos de la pendiente. En el interior de estos grandes espacios se identificaron actividades de consumo, preparación de alimentos, así como también el procesamiento de materias primas.

Una característica importante en el conjunto de sitios en terrazas es que alternan su localización en sectores de las márgenes del río Grande y también pueden disponerse en el interior de quebradas por lo que resulta notoria la escasa visibilidad hacia el entorno y desde los sitios en particular. Este último aspecto es característico de poblados como Sarahuaico (Rivolta 1996), Aguirre (Rivolta 2003b), Quebrada del Cementerio, Campos Colorados (Nielsen 1997; Nielsen y Rivolta 1997), entre otros. En menor proporción se encuentran asociados a las laderas aterrazadas, emplazamientos de menor envergadura con particularidades defensivas y/o de control visual como sería el caso de Puerta de Maidana Alto (Aleksandrowicz 1987b), Sarahuaico Alto y Pucará de Perchel (Debenedetti 1918b; Scaro y Sica 2015).

La cerámica corresponde principalmente a fragmentos ordinarios de ollas y pucos y, en menor proporción, a vasijas decoradas. Los fragmentos de pucos negro pulidos constituyen parte del conjunto, así como también se cuenta con escasos fragmentos que podrían adscribirse al estilo Yavi, Algunos conjuntos incluyen dameros, manos, triángulos sólidos y reticulados en general negro sobre rojo y también pintados en negro y blanco sobre rojo. Hasta el momento, no se registraron en estos sitios estilos como Angosto Chico Inciso, ni Poma negro sobre rojo.

Los sitios representativos de este grupo que cuentan con fechados radiocarbónicos son: Alto de La Isla (Rivolta 2000, 2003b), Puerta de Maidana (Schuel 1930; Aleksandrowicz 1987b; Rivolta 2003b), Banda de Perchel (Rivolta 1997, 2003b), Sarahuaico (Rivolta 1996, 2003b), Quebrada del Cementerio, Campos Colorados (Nielsen 1997; Nielsen y Rivolta 1997), La Señorita (Nielsen 1996, 1997; Nielsen y Rivolta 1997), Pucará de Perchel (Debenedetti 1918b; Scaro y Sica 2015) y Angosto Chico (Casanova 1942a; Rivolta et al. 2010b). En tanto que el sitio Aguirre (Rivolta 2003b) aún no cuenta con dataciones radiocarbónicas.

\section{Ocupación en semiconglomerados}

Los sitios que componen este conjunto muestran una organización de carácter comprimido con una densidad de recintos dispuestos sobre un sector nivelado, sugiriendo un grado de compactación similar al de los grandes conglomerados, pero en superficies no mayores a dos hectáreas. Los espacios seleccionados para la instalación de estos poblados comprenden sectores ameseta- 
dos en cerros contiguos al curso del río Grande de Jujuy o en morros bajos, tal como los casos de La Isla de Tilcara, que se ubica en la playa del mencionado curso fluvial o el sitio Huacalera, similar al anterior, pero en la banda opuesta del río. Otras evidencias proceden de rescates en la planta urbana de Tilcara y están asociados a inhumaciones aisladas como los sitios El Manzano y Hotel Las Marías (Otero y Rivolta 2015). En estos dos últimos, si bien no se cumple la condición de semiconglomerados, registramos inhumaciones con alfarería semejante a los restantes sitios considerados.

El conjunto de piezas representativas cuenta mayormente con datos de procedencia y está conformado por escudillas, vasos, platos, jarras y modelados antropomorfos y zoomorfos (Rivolta 2003a), entre los cuales se presentan formas novedosas en la región, tal como los vasos denominados reloj de arena. La iconografía generalmente es geométrica, con motivos de líneas paralelas y reticulados en negro sobre rojo o en blanco y negro sobre rojo, así como también se presenta en piezas modeladas, del tipo antropomorfo y zoomorfo, entre otros. En una relación minoritaria respecto del total se encuentran piezas que se identifican con ejemplares cerámicos del altiplano boliviano, propios de los estilos Yura, así como de otros conjuntos que podrían proceder del norte de Chile, incluyendo además estilos reconocidos como el Yavi (Rivolta et al. 2017).

Los sitios que representan este grupo y que se encuentran fechados son: La Isla de Tilcara (Debenedetti 1910; Rivolta 2000), El Manzano (Otero y Rivolta 2015), Hotel Las Marías (Otero y Rivolta 2015) y Keta Kara (Pelissero 1995). Aquellos sitios que comparten evidencias arqueológicas, pero no se encuentran datados son: Huacalera (Rivolta 2003b), Puerta de Juella (Casanova 1937; Raffino 1991), Calle Jujuy, Estación Tilcara del Ferrocarril (Boman 1908; Rivolta 2003a) e Iglesia Parroquial de Tilcara y Calle Belgrano (Otero y Rivolta 2015).

\section{Ocupación en conglomerados}

La característica más representativa en este grupo es la presencia de sitios clásicamente denominados "pucará" o grandes conglomerados (Madrazo y Ottonello 1966). Tradicionalmente, el emplazamiento en altura se interpretó como una manifestación en torno al conflicto (Ottonello y Lorandi 1987; Olivera y Palma 1997; Tarragó 2000; Nielsen 2001). Aunque, muchos de ellos presentan la particularidad de contar con un destacado control visual del entorno sin que esta característica los convierta necesariamente en sitios defensivos. Por lo que no se puede descartar que los emplazamientos estén correlacionados con los factores propios de la geodinámica del paisaje, más allá de los tradicionalmente propuestos. Por ejemplo, en la zona del fondo de valle en Tilcara es común registrar ocupaciones, sepultadas a varios metros de profundidad, como resultado del deslizamiento producido por flujos torrenciales, la actividad de los conos de deyección y las crecidas fluviales (Rivolta et al. 2017). De allí que un factor condicionante para la construcción de los poblados haya sido la selección de áreas de menor riesgo ambiental. La recurrencia de estos fenómenos ha sido constante a lo largo del tiempo y fueron registrados en la cordillera Oriental durante el cuaternario entre los 35.000 y 25.000 años AP y luego de los 5.000 años AP (Trauth et al. 2000; Sancho et al. 2008).

En cuanto a la estructura interna, los conglomerados exhiben una alta densidad de recintos, en superficies que varían entre diez y quince hectáreas, asociados a una organización en la que se destacan sectores específicos tales como plazas, espacios formalizados de descarte, caminos y sectores de inhumación, ya sean entierros en espacios habitacionales y/o en cementerios. El estado actual del conocimiento y la gran cantidad de excavaciones sistemáticas recientes en este tipo de emplazamientos permiten diferenciar los contextos sobre la base de las características de la materialidad asociada y evaluar sus tendencias temporales por separado. Tal como referimos en la metodología, en primer lugar, integramos en el subgrupo D1 a los espacios formalizados 
de descarte o basurales, ya que por sus particulares procesos de formación es muy difícil deslindar la asociación entre fechados y los hallazgos arqueológicos diagnósticos. Por lo general, las evidencias referidas a contextos de descarte aún son escasas en la región, un ejemplo de este subgrupo estaría representado por el Pucará de Tilcara (Casanova et al. 1976; Tarragó y Albeck 1997) así como también por el sitio La Huerta (Raffino y Alvis 1993).

Por otro lado, el subgrupo D2 incluye espacios habitacionales y funerarios sin evidencia de material inca. En estos, la alfarería se caracteriza por estilos bicolores en negro sobre rojo, representada en cántaros, pucos, ollas y cuencos. Las piezas restringidas, definidas para el estilo Humahuaca negro sobre rojo presentan diseños reticulados, círculos concéntricos y banderines (Otero 2017). También se reconocen motivos incisos, propios de las vasijas Angosto Chico Inciso, que pueden ser tanto de manufactura local como no local. Las formas abiertas exhiben un amplio repertorio decorativo estructurado de manera bipartita o cuatripartita. Abundan los motivos pintados en negro con líneas cortas oblicuas colocadas sobre una línea fina, los triángulos con apéndices paralelos y los círculos concéntricos. Entre las piezas abiertas aparecen con frecuencia los pucos Interior Negro Pulido y los Poma negro sobre rojo, que poseen bandas sólidas en las superficies externas. Los conjuntos cerámicos a su vez cuentan con un importante número de piezas restringidas del tipo ordinario y monocromo. Este último representado en su mayoría por morados, castaños y rojos pulidos o alisados.

Entre los sitios representativos de este subgrupo se pueden mencionar: Pucará de Tilcara (Ambrosetti 1908; Debenedetti 1930; Krapovickas 1958-59, 1980-81; Madrazo 1969b; Tarragó 1992; Otero 2015), Huichairas (Casanova 1934; Mercolli et al. 2014), Pucará de Hornillos (Casanova 1942b), Juella (Cigliano 1967; Pelissero 1969; Leibowicz 2013) y Los Amarillos (Marengo 1954; Nielsen 1997, 2006; Nielsen y Walker 1999; Taboada y Angiorama 2003), entre otros.

El subgrupo D3 incluye contextos con evidencia inca. En la sección central de Quebrada de Humahuaca gran parte de las evidencias referidas a la ocupación incaica destacan una impronta cuzqueña adaptada a las condiciones locales. Si bien existen pocos sitios habitacionales en el sector para los que se pueda aseverar que fueron erigidos durante este intervalo, resulta común registrar determinadas características constructivas que se sobreimprimen a otras correspondientes al grupo previamente mencionado y que, en general, resultaron novedosas para la región (Ochoa 2017, 2019). Asimismo, se edificaron estructuras especiales en sectores de los poblados, utilizando espacios disponibles, ampliando construcciones y aplicando criterios de organización del espacio diferenciales respecto a los precedentes. También se identifican áreas específicas de uso político ceremonial, como es el caso de "La Iglesia" del Pucará de Tilcara que responde al modelo de rectángulo perimetral compuesto (Madrazo y Ottonello 1966; Otero y Ochoa 2011; Otero 2015), o el sector próximo a la cima del sitio con actividades de producción artesanal especializadas entre los cuales se encuentra el taller de Lapidario (Krapovickas 1958-59, 1981-82) y numerosas casas-taller destinadas a la producción de objetos suntuarios confeccionados en metales y en rocas marmóreas, sílices, ónix, obsidianas, travertinos, alabastros, entre otras (Otero y Tarragó 2017; Ochoa y Otero 2020; Otero et al. 2021a). Otros espacios que responden a la remodelación del entorno como causa de la ocupación inca son el sector A en el sitio La Huerta, que de acuerdo a Palma (1998) comprende edificios relacionados a dicha presencia, o el Complejo A del sitio Los Amarillos, reformulado a partir de un episodio de violencia simbólica durante la ocupación incaica (Nielsen 2006).

La cantidad de talleres instalados en el Pucará de Tilcara, la compleja cadena operativa identificada en cada uno de ellos, la circulación de variadas materias primas y de bienes manufacturados, sumados a todas las materialidades y geosímbolos identificados en el paisaje del sector central de la Quebrada de Humahuaca son parte de los indicadores necesarios para caracterizar la matriz productiva a nivel regional (Ochoa y Otero 2020). Asimismo, la marcada presencia de objetos de filiación cuzqueña en los centros administrativos y de piezas cerámicas de los estilos 
regionales que circularon por los Andes meridionales, como el Pacajes, Yavi-Chicha y el Negro Pulido, y la aparición de nuevas tecnologías líticas en Tilcara podrían manifestar la existencia de grupos de mitimaes, dedicados de manera exclusiva a fortalecer la especialización artesanal y la producción agrícola.

Las características de la alfarería para este momento responden a piezas que reproducen atributos incaicos entre los que se cuentan platos ornitomorfos, aríbalos, pelikes, jarras y pucos de grandes asas acintadas. A su vez, continúa la producción de cántaros, escudillas, ollas y cuencos manteniendo la identidad local. Si bien las transformaciones estilísticas en los conjuntos locales a primera vista parecerían incluir simplemente variantes morfológicas, resulta notoria la modificación y recombinación de los motivos decorativos propios de la región para momentos previos a la anexión incaica (Otero 2017). A pesar de ello, la cerámica local no fue objeto de interés por parte del Estado ya que los estilos de la Quebrada no circularon extrarregionalmente como lo hicieron otros, entre los que se cuentan el Yavi-Chicha, el Pacajes y el Negro Bruñido.

Tal como se mencionó, los sitios más representativos son: Pucará de Tilcara (Ambrosetti 1908; Debenedetti 1930; Krapovickas 1958-59, 1980-81; Madrazo 1969b; Tarragó 1992; Otero 2015; Otero et al. 2018), La Huerta (Lafón 1954; Palma 1998; Raffino y Alvis 1993), Yacoraite (Krapovickas 1969), Campo Morado (Debenedetti 1918b; Palma 2003; Palma et al. 2006; Fernández do Rio 2009), y Los Amarillos (Marengo 1954; Nielsen 1997, 2006; Nielsen y Walker 1999).

Por último, han sido datados por radiocarbono unos pocos contextos con evidencia colonial (subgrupo D4). No obstante, a pesar de esta falta de fechados, se sabe sobre la base de datos históricos más precisos que la llegada de los españoles a la región se produjo en 1536. La información arqueológica es exigua en lo que atañe a la sección central de la Quebrada de Humahuaca, restringiéndose a restos materiales en contextos de inhumación. En cuanto a los hallazgos se centran en objetos tales como cuentas de collar de vidrio, elementos fabricados en hierro, fragmentos de textiles como batista y terciopelo, y semillas de uva. Por lo general, estos materiales se encuentran asociados con elementos locales entre los que se reconocen piezas cerámicas con influencia incaica y otras del conjunto local.

Hasta el momento en el sector que nos ocupa, las evidencias más relevantes están contenidas en sitios como el Pucará de Tilcara (Otero et al. 2021a y b) y La Huerta (Palma 1998). En el Pucará se registraron discos de metal con motivos decorativos que emulan imágenes europeas y hasta el entierro completo de un bovino. También es frecuente la incorporación de cerámicas que presentan diseños iconográficos que rompen con la estructuración estilística de la última época prehispánica (Otero et al 2021b). En cuanto al registro material en La Huerta, Palma (1998) hace mención del contexto funerario en el que se incluyen como acompañamiento, cuentas venecianas variadas en asociación con material incaico y de manufactura local.

Con respecto a los fechados radiocarbónicos resultan insuficientes y de dificultosa interpretación dado que requieren rangos acotados sumado al abordaje de un conjunto de evidencias que se presentan, hasta el momento, solo en contextos de inhumación contenidos en recintos, generalmente combinando elementos Incas, locales y europeos.

Los sitios que forman parte de este grupo son: La Huerta (Palma 1998) y el Pucará de Tilcara (Ambrosetti 1908; Schuel 1930; Tarragó 1992; Otero 2017; Otero et al. 2021 a y b).

\section{TENDENCIAS TEMPORALES}

Con un índice Amodel de 92,3\%, el modelo aquí propuesto y la agrupación de fechados es aceptable globalmente siguiendo a Bronk Ramsey (2009), quien considera como tal un índice mayor a $60 \%$. Solo hay tres fechados que podrían considerarse marginales porque tienen un bajo índice de ajuste individual con respecto a su grupo. Se trata del fechado 19 dentro del grupo D2, 


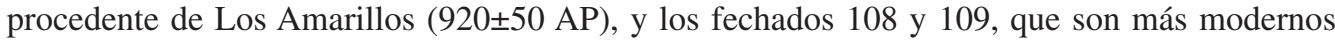
que el resto del grupo D3. Es posible retirar esos fechados del modelo, aunque siendo tan pocos casos dentro de una muestra grande de fechas observamos que su efecto es despreciable. Es así que para discutir los resultados tomamos los rangos de $68,3 \%$ de probabilidad y los promedios de cada límite inicial y final, aunque debe entenderse como una estimación ya que el método y los datos disponibles por ahora permiten calcular la mayoría de esos parámetros con un amplio margen de error.

Para el grupo A de las aldeas contamos hasta ahora con solo nueve fechados radiocarbónicos aceptables para un proceso que pudo durar entre 950 y 1140 años, habiendo iniciado en algún momento entre el 100 a.C. y el 150 d.C. (figura 2). El final en la ocupación de este tipo de sitios -y/o del uso de materiales anteriormente considerados como Formativos o Tempranos- se puede ubicar entre 1110 y 1320 d.C. Aunque es un margen de error bastante grande que se deberá precisar en el futuro, los datos actuales permiten sostener que las aldeas se mantuvieron ocupadas -y que ese material circuló- por más tiempo del que pensábamos, incluso cuando otros modos de vida muy diferentes ya estaban hace tiempo instalados.

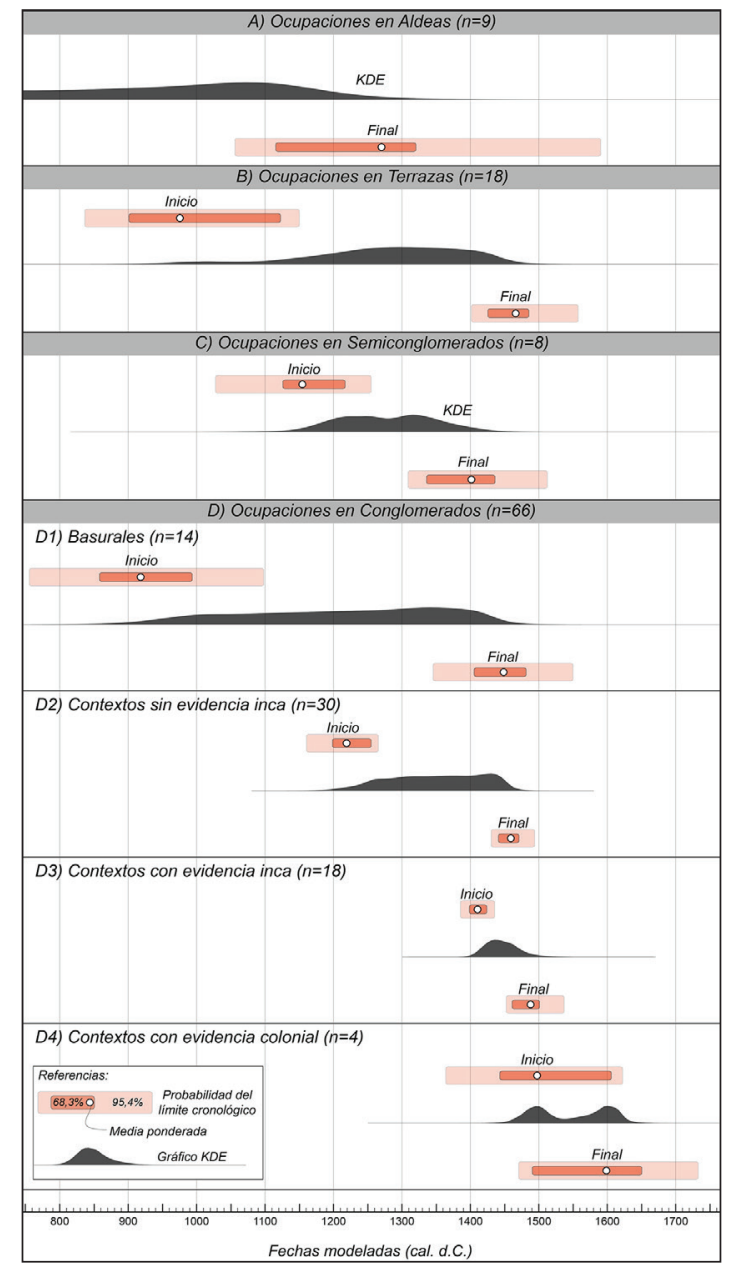

Figura 2. Rangos de probabilidades modelados para el Inicio y Final de cada tipo de sitios o contextos y gráficos KDE que sintetizan todos los fechados radiocarbónicos del grupo. El Inicio del grupo A no está graficado por la escala utilizada, pero sus valores se encuentran en la Tabla 2 
El grupo B de las terrazas se inicia entre el 900 y el 1020 d.C. (con un 67,3\% de probabilidad, solo hay un $1 \%$ de que comenzara en el Siglo XII) y fue un proceso que duró alrededor de 440 años. El gráfico KDE muestra una máxima probabilidad entre los siglos XIII y XIV y podríamos hipotetizar que se trata del momento de máxima ocupación de este tipo de sitios. El final se estima entre 1420 y 1490 d.C. en relativa coincidencia con el final de otros grupos y el inicio de la presencia incaica en la región.

El grupo C se inicia entre el 1120 y el 1220 d.C. Este tipo de ocupación duró alrededor de 200 años, pero la mayoría de los datos se concentran en dos momentos, uno hacia fines del siglo XII y principios del XIII y otro a mediados del siglo XIV. Será importante seguir estudiando este tipo de contextos para precisar estas tendencias y deslindar si se trata de ocupaciones continuas o separadas. El fin de las ocupaciones en semiconglomerados fue entre 1330 y 1440 d.C., pudiendo ser unos años antes o en coincidencia con la llegada de los incas a la región. La separación temporal con el periodo Inca también se corrobora con el estudio de los contextos funerarios porque hasta ahora no se ha registrado la asociación de material Isla con material incaico.

Las primeras ocupaciones en los Conglomerados están representadas en sus basurales (D1) desde algún momento entre el 850 y el 1000 d.C., aunque no sabemos con certeza cómo era la configuración de los poblados durante esos siglos. Con catorce fechados se puede observar un uso continuo de este tipo de contextos por alrededor de 460 años, abarcando un rango similar al del grupo B. En cambio, la ocupación de los espacios habitacionales y funerarios (grupo D2) comenzó posteriormente y de todos los procesos es el que puede ser estimado con mayor precisión ya que se trata del grupo con mayor cantidad de fechados y contextos estudiados en los últimos años. El inicio se puede estimar con mucha certeza hacia principios o mediados del siglo XIII (entre 1190 y 1260) y la ocupación pudo durar entre 180 y 250 años hasta 1440-1480 d.C. El gráfico KDE muestra probabilidades bastante homogéneas, lo que podría interpretarse como una ocupación continua a nivel regional durante todo este tiempo.

Una tendencia destacable es la similitud cronológica entre los grupos $\mathrm{C}$, correspondientes a los semiconglomerados y D2 (figura 3), que corresponden a tipos de sitios que todos los marcos cronológicos previos postularon como sucesivos y no contemporáneos. El inicio de los semiconglomerados podría ser unos 70 años antes, aunque la diferencia entre unos y otros todavía está dentro del margen de error de las mediciones. También es evidente que la ocupación de C terminó unas décadas antes que D2.

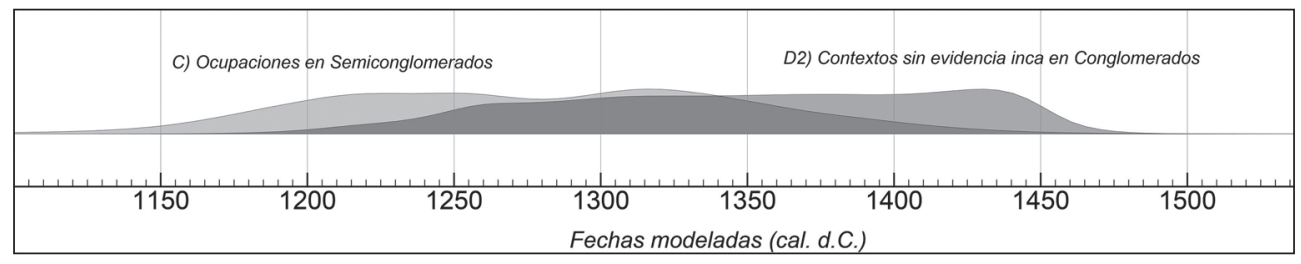

Figura 3. Superposición de gráficos KDE entre los contextos sin evidencia inca en conglomerados y los semiconglomerados

En cuanto a los contextos con material inca (grupo D3), los fechados disponibles son coherentes con una ocupación breve desde principios del siglo XV hasta inicios del XVI. La presencia incaica es un marcador muy importante en todos los marcos cronológicos de la región, por la visibilidad de su impronta y los grandes cambios que suscitó. Sin embargo, también podemos observar una superposición cronológica de al menos 50 años entre este grupo y algunos de los otros (figura 4) señalando una distribución diferencial de las evidencias inca a nivel regional. 
Del último grupo D4, correspondiente a los contextos con material europeo, poco se puede decir desde el radiocarbono ya que son solo cuatro fechas que apuntan claramente hacia mediados del siglo XVI, pero además la curva de calibración para estos siglos no es muy precisa. Por lo tanto, la discusión sobre la cronología de la conquista es mejor sustentarla por ahora en base a los datos historiográficos.

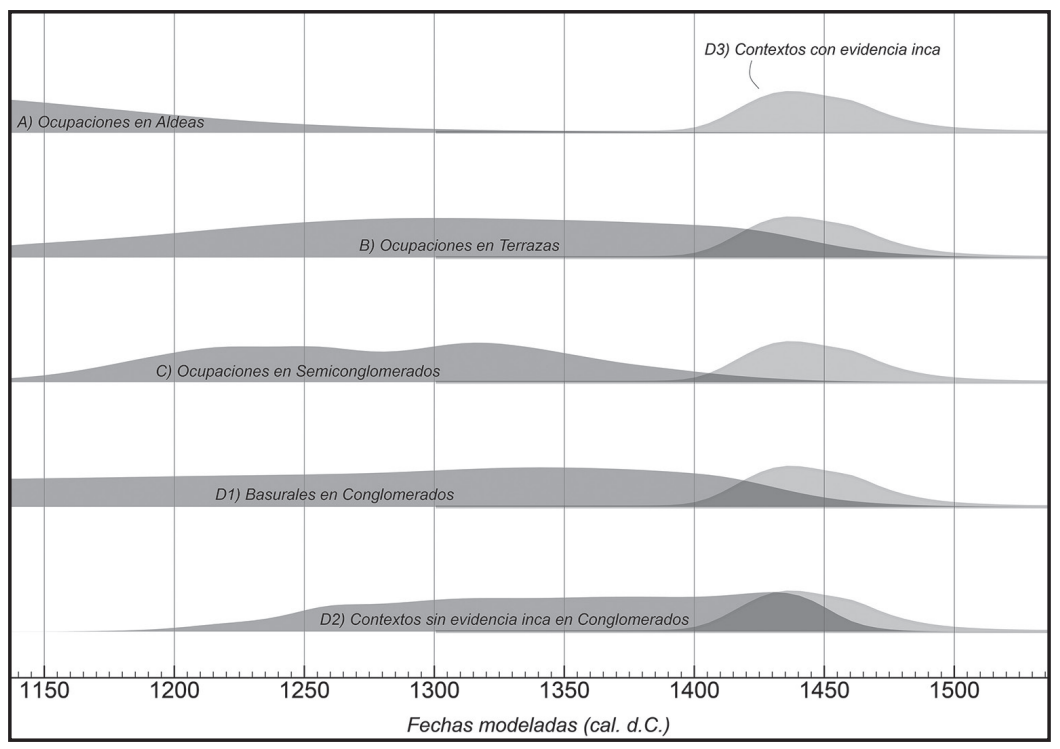

Figura 4. Superposición de gráficos KDE entre los contextos con evidencia inca y otros tipos de ocupaciones

\section{PROPUESTA CRONOLÓGICA}

Las evidencias con las que se cuenta hasta el momento permitieron avanzar en un esquema de periodificación partiendo de la elaboración de un conjunto de hipótesis de trabajo que vinculan los diferentes eventos e intervalos. Los períodos construidos son cinco y se organizaron tomando en cuenta la correlación de las tendencias temporales observadas en cada grupo (figura 5). Los límites temporales de los períodos se expresen en años aproximados o siglos, ya que en general entendemos que no hubo cambios abruptos entre uno y otro, sino que reflejan procesos graduales.

Período 1: 100 a.C.-900 d.C.

El primer período abarca un rango temporal amplio desde inicios del primer milenio hasta aproximadamente el año 900 d.C. (siglo X) y se constituye como el momento en que se registran los primeros grupos agroalfareros. Desde el punto de vista conceptual, este período correspondería al momento de ocupación de aldeas, aunque también se incluyen otros poblados para los cuales es dificultoso reconocer la fisonomía del sector más antiguo debido a que se trata de sitios multicomponentes. Además de lo que precisamos previamente sobre la noción de aldea, consideramos que se trata de una forma de organización ligada a la explotación de recursos agropastoriles, tratándose de grupos humanos que compartieron tanto espacios contiguos como estructuras de vivienda dispersas en sectores agrícolas. Sin embargo, restan efectuar investigaciones que den 


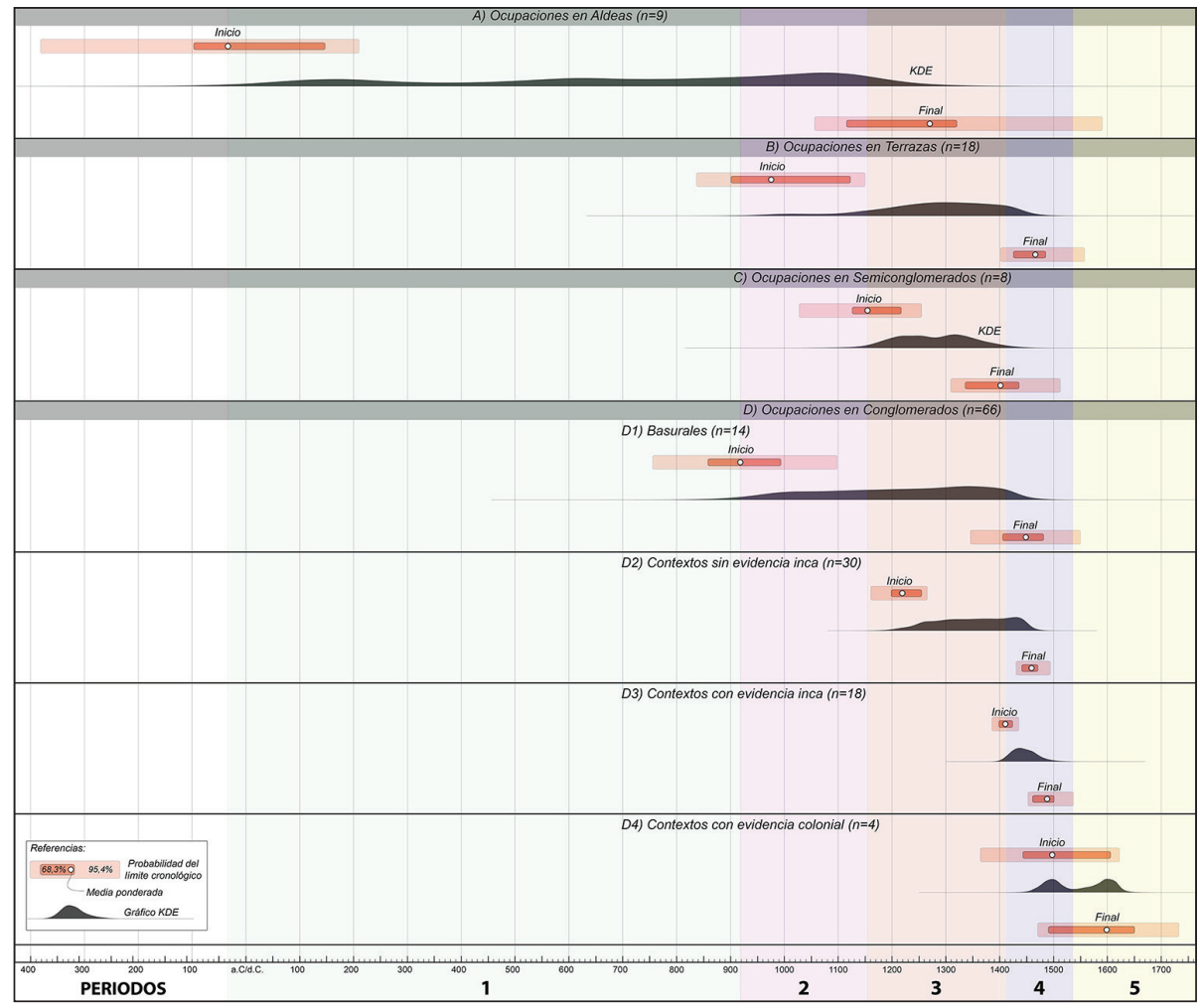

Figura 5. Propuesta de periodificación

cuenta del modo en que se fueron consolidando los poblados durante un intervalo tan extenso y los cambios que pudieron tener lugar durante este.

Desde las evidencias disponibles es posible identificar sitios como Alfarcito y Estancia Grande $\mathrm{y}$, en el sector de fondo de valle, los contextos urbanos de Tilcara. Anteriormente, Olivera y Palma (1997) plantearon esta distinción en la instalación afirmando que los fechados radiocarbónicos resultaron más antiguos en los sitios localizados en las quebradas altas. Asimismo, destacaron una diferencia en el manejo tecnológico agrícola del fondo de valle respecto de las quebradas altas dado que en este último caso el panorama es de mayor estabilidad ambiental, libre de aluviones (Olivera y Palma 1997). Estos fenómenos pudieron detectarse en el registro arqueológico de Tilcara ya que los flujos de barro impactaron puntualmente en los sectores seleccionados por estas sociedades tempranas (Rivelli y Zelarayan 2016). Diversos hallazgos dan cuenta de estos episodios, algunos de los cuales inclusive produjeron importantes hiatos entre ocupaciones (Madrazo 1968).

En síntesis, las evidencias con las que contamos aún no permiten ahondar en particularidades respecto a este período, pero creemos importante no dejar de lado la perspectiva referida a los cambios que pudieron tener lugar no solo en el sector de emplazamiento, sino también en la forma cómo los grupos se organizaron espacialmente en el interior de los poblados. Hasta el momento, el planteo referido a viviendas dispersas en áreas agrícolas no pareciera aplicarse tan claramente en la planta urbana de Tilcara, sino que más bien estaría apuntando a un conjunto de estructuras junto al curso del río Grande, concentradas en el ángulo noreste del cono de deyección, sustrato sobre el cual se localizan hasta el momento las evidencias disponibles. 
Período 2: 900-1200 d.C.

Este período podría caracterizarse por la coexistencia de poblaciones asentadas en aldeas y paulatinamente reorganizadas en sitios en terrazas sobre las laderas medias, próximas a los cursos fluviales. Es probable que durante este período las aldeas se encontraran en su máximo desarrollo, pero a la vez el escenario estuviera sufriendo transformaciones a partir de la reconfiguración de los espacios y la dinámica poblacional en general. Entre otros aspectos, las modificaciones se plasmaron en un tipo de ocupación caracterizada por espacios habitacionales en desniveles o terrazas, constituyendo el punto de partida de un conjunto de sitios que con el tiempo siguieron trayectorias disímiles. Durante este período, los sitios en terrazas se caracterizaron por ocupar faldeos en proximidad al curso del río Grande, lo que además representa la cercanía con el fondo de valle en el que se disponen espacios de cultivo. A lo largo de los siglos, estos poblados mantuvieron su estructura general, pero la selección de los emplazamientos varió notablemente, situación que se consolidó durante el siguiente período.

En cuanto al contexto material, las diferencias no resultan significativas al comparar la cerámica propia del momento aldeano respecto a la producida durante la ocupación en terrazas. Se evidencia una continuidad en aspectos tales como la preponderancia de estilos ordinarios sobre los decorados a la vez que, a lo largo de este período se daría inicio a un motivo decorativo que tuvo amplia representación en la región tal como es el diseño reticulado. Asimismo, pierde representatividad el único estilo pintado en negro sobre rojo propio del momento anterior caracterizado por líneas paralelas combinadas con líneas quebradas.

Junto con los sitios en terrazas domésticas, durante este período se originaron los sectores identificados como áreas de descarte de los que más adelante se convirtieron en grandes conglomerados, marcando el inicio de la ocupación en estos emplazamientos. El caso particular del basurero del Pucará de Tilcara da cuenta no solo de la estructura de descarte en sí misma, sino también de posibles evidencias sepultadas que pudieran indicar ocupaciones previas (Tarragó y Albeck 1997). Del mismo modo, algunos sectores de las laderas de los conglomerados en formación muestran posibles estructuras aterrazadas, condición que permite plantear la hipótesis de una instalación de este tipo que luego fue reutilizada, abandonada o sufrió deterioro debido a las pendientes sobre las que se ubican. Esta condición puede reconocerse en las laderas norte y sudoeste del Pucará de Tilcara, pero también en las proximidades del sector de descarte de La Huerta (Rivolta 2004), que cuenta con espacios aterrazados en cercanía al basurero denominado PS1 (Raffino y Alvis 1993).

Período 3: 1200-1400 d.C.

Durante los siglos venideros, se produjeron diferentes acontecimientos en el sector central de la Quebrada de Humahuaca, que consolidaron un período altamente dinámico. Es fundamental comprender que estos eventos fueron contemporáneos, entre ellos se cuenta el inicio de la ocupación de los sitios denominados semiconglomerados, el máximo de la ocupación de los sitios en terrazas domésticas que surgieron durante el período anterior, la consolidación de los grandes conglomerados y el final de la ocupación de las aldeas. Esta dinámica posiblemente se exteriorizó a partir de un crecimiento poblacional sostenido, la ocupación del espacio con emplazamientos heterogéneos y modalidades de instalación altamente diversificadas. De este modo, durante el período 3, se identifica el siguiente conjunto de sitios: semiconglomerados con origen foráneo (ej.: La Isla de Tilcara), conglomerados de carácter local (ej.: Pucará de Tilcara, La Huerta), sitios en terrazas domésticas (ej.: Angosto Chico, Sarahuaico) y, por último, el final de las ocupaciones aldeanas. En este último caso, será necesario contar con nuevas evidencias a fin de ajustar el momento en que estos sitios fueron abandonados. 
Durante el período 2 surgen los sitios en terrazas y, si bien definimos el actual período como el de máxima ocupación de estos poblados, también en él se verificaron cambios significativos. El mosaico de situaciones registradas comprende sitios aterrazados en vías de abandono o abandonados, otros que se modificaron para dar lugar a grandes conglomerados, y algunos que mantuvieron sus características iniciales continuando la ocupación. Asimismo, se destaca un cambio en la disposición ya que, de ubicarse en proximidad del curso del río Grande en el período anterior, comienzan a emplazarse en quebradas tributarias, en particular en sectores de dificultosa localización y visualización. Durante el transcurso de este período, en algunos de estos sitios se emplazaron estructuras en sectores de alto control visual por encima de las laderas aterrazadas, en casos como Sarahuaico Alto y Puerta de Maidana Alto (Aleksandrowicz 1987b).

Las hipótesis planteadas en relación con cambios ambientales (Nielsen 2007) o conflictos intra e intergrupales (Ottonello y Lorandi 1987; Nielsen 2001; Olivera y Palma 1997; Tarragó 2000), podrían haber representado el disparador que marcó el preludio del abandono de determinados sitios en terrazas, tema para el cual existe cierto consenso entre los investigadores (Nielsen y Rivolta 1997; Rivolta 2003a; Nielsen 2007). Si bien las situaciones de conflicto pudieron causar un reagrupamiento poblacional en aquellos sitios seleccionados por alguna característica o condición relevante (emplazamiento, control territorial, recursos, etc.), nos inclinamos a sostener que los factores climáticos, en particular las características geodinámicas de la región y el frecuente número de aluviones, fueron los factores que principalmente llevaron a remodelar una gran cantidad de espacios para albergar un número creciente de individuos.

Considerando el proceso de conformación de los grandes conglomerados, resulta necesario pensarlos como sitios que se complejizaron gradualmente. De este modo, es posible identificar el resultado de una sumatoria de eventos a lo largo de varios siglos, condición que pareciera no haber tenido lugar en otros poblados de la región. De allí que, la estrategia de disociar el análisis de las evidencias en sectores, tal como se planteó en el apartado metodológico, constituye una vía que permite comprender su estructuración sin que esto signifique desvincular los procesos que tuvieron lugar a lo largo del tiempo.

Tal como se señaló para el período anterior, el inicio de la ocupación de los conglomerados pareciera haberse producido en sectores acotados de la totalidad del espacio disponible, condición registrada en la principal área de descarte del Pucará de Tilcara (Tarragó y Albeck 1997) y de La Huerta (Rivolta 2003b; Rivolta 2004). Posteriormente, como parte de los eventos de este período, se produce la ocupación de gran parte de las áreas disponibles, principalmente los sectores nivelados con espacios residenciales, caminos, plazas, etc.

A la par, se inicia la ocupación en sitios semiconglomerados que planteamos como instalaciones de grupos no locales, mostrando particularidades en la organización y en los contextos recuperados, lo que marca un contraste importante respecto a los desarrollos locales. Es sabido que, a partir del siglo XII, el Área Andina Centro Sur constituyó el escenario de un cambio drástico originado por la caída de Tiahuanaco (Janusek 2005). La fragmentación y el colapso fueron el resultado de múltiples procesos interdigitados producto de una larga trayectoria de desarrollo y consolidación de un estado que exacerbó tensiones sociales preexistentes. Es así que se convirtió en una época de innovación cultural caracterizada por una larga secuencia de eventos sostenidos a lo largo de varias generaciones (Janusek 2005). En este sentido, son numerosas las contribuciones que han dado cuenta de este proceso, entre las cuales se encuentran las que consideran que el cambio climático podría haber constituido un factor desencadenante del ocaso de Tiahuanaco. Los eventos de aridez y bajas temperaturas entre los siglos XII y XV d.C. (Binford et al. 1997; Kolata y Ortloff 2003; Engel et al. 2014) sumado a otros de índole sociopolítico y la drástica reducción en la productividad agrícola, obligaron a la población altiplánica a diversificar recursos, en especial hacia el pastoralismo (Stanish 2003; Arkush 2008). Estas razones, entre otras, produjeron el desplazamiento de poblaciones (Owen y Goldstein 2001; 
Janusek 2005; Owen 2005; Smith y Janusek 2014; Sharratt 2016) desde el área del Titicaca hacia nuevas comunidades y redes de asentamientos dispersas, cuyo inicio se produjo hacia fines del 1100 d.C. (Janusek 2005) en dirección a áreas poco habitadas con la instalación de aldeas pequeñas, dispersas y defendibles.

Consideramos que la Quebrada de Humahuaca constituyó, entre otras, un área de vacancia favorable al desplazamiento de grupos altiplánicos (Rivolta et al. 2017), en el que se vieron involucrados los grupos humanos que dieron origen a sitios semiconglomerados como La Isla de Tilcara, Keta Kara y Puerta de Juella, entre otros. La aparición de estos grupos, en los que pueden reconocerse características propias de los procesos migratorios (Owen 2005), marcó un contraste con las poblaciones locales asentadas en la región. Un elemento clave vinculado a las migraciones en contextos arqueológicos es el surgimiento de materialidades de manera abrupta en asentamientos con características diferenciales, sin que exista un registro previo en el ámbito local (Owen 2005). Los trabajos de autores como Anthony (1990) y Cameron $(1995,2013)$ efectuaron aportes valiosos para la integración del tema migratorio a los estudios arqueológicos. Principalmente abordando aspectos teórico metodológicos concernientes a las corrientes, tanto las que involucran distancias cortas como largas y, dentro de esta última, las diferentes variantes y los procesos de retorno involucrados. Otros autores plantean la problemática directamente ligada a las condiciones que se presentaron en los Andes Centro Sur con posterioridad al primer milenio de la era (Blom et al. 1998; Knudson et al. 2004; Owen 2005; Knudson 2008; Goldstein 2015).

Esta situación parecería reflejar la problemática concerniente a los semiconglomerados y su evidencia material. Es decir, que estamos considerando como hipótesis de trabajo que hacia el siglo XIII el sector central de la Quebrada de Humahuaca, representó un espacio de convergencia de grupos que convivieron en proximidad, pero con características sustancialmente diferenciales entre sí. Desde la perspectiva de la materialidad, las comunidades Isla se instalaron configurando sitios habitacionales con una modalidad de alta concentración de estructuras en superficies niveladas no mayores a 2 ha. Asimismo, el conjunto alfarero pasó a constituirse por piezas con formas novedosas tanto en lo que refiere al aspecto formal como iconográfico. Estas comunidades Isla mantuvieron su ocupación a lo largo de dos siglos, ya que los resultados radiocarbónicos efectuados sobre los contextos materiales dan cuenta de una permanencia prolongada que incluye el espacio delimitado en la planta urbana de Tilcara, aunque en este último caso se trata de contextos aislados de inhumación (Rivolta et al. 2017).

Otros elementos que podrían aportar información a fin de testear la hipótesis son los estudios bioantropológicos centrados en la estructura social de las poblaciones prehispánicas. Las publicaciones han tratado la temática de los vínculos que tuvieron lugar a lo largo del tiempo entre poblaciones prehispánicas en general, aunque concentrados en particular desde el primer milenio de la era en adelante (Cocilovo et al. 2017 a y b, 2019). Recientemente, el análisis sobre una muestra de 947 individuos realizada por Cocilovo y colaboradores (2019) permitió avanzar sobre aspectos de la residencia postmarital en el NOA. En este estudio se proponen patrones de residencia patrilocal y matrilocal determinados por tasas migratorias que afectaron la estructura social y que para el caso de la Quebrada de Humahuaca remite a un desplazamiento mayoritario de hombres, sostenido en el tráfico de personas e intercambio de productos.

Otro aspecto para considerar son las evidencias de deformaciones craneanas propias de la región altiplánica, en el ámbito que nos ocupa. El estudio de las prácticas deformatorias para el altiplano fue tratado en diferentes publicaciones (Allison et al. 1981; Blom et al. 1998; Knudson et al. 2004; Blom 2005), inclusive en diccionarios antiguos de la lengua aymara, de acuerdo a lo señalado por Blom (2005). Esta autora destaca tres variantes en la deformación del cráneo que se agrupan en las categorías: no modificado, fronto-occipital o tabular oblicua y anular. De acuerdo a los estudios llevados a cabo, Blom (2005) detecta un patrón de deformación fron- 
to-occipital o tabular oblicua en la región de Moquegua; anular en el Valle de Katari hacia el noreste de Tiahuanaco y en lo que correspondería al sitio Tiahuanaco propiamente se registrarían ambos tipos de deformaciones. Asimismo, destaca el registro de variantes del tipo anular en San Pedro de Atacama, así como también en Cochabamba, comprendiendo ámbitos con evidencias materiales Tiahuanaco. Para el caso de la Quebrada de Humahuaca, las escasas evidencias de tipo bioarqueológico con las que se cuenta para los semiconglomerados no permite avanzar en resultados concluyentes, no obstante, es llamativa la presencia de deformaciones que no fueron registradas a lo largo de las diferentes épocas en la Quebrada de Humahuaca y que forman parte de los contextos de inhumación de La Isla de Tilcara y Keta Kara (Dillenius 1913; Imbelloni 1932) (figura 6).

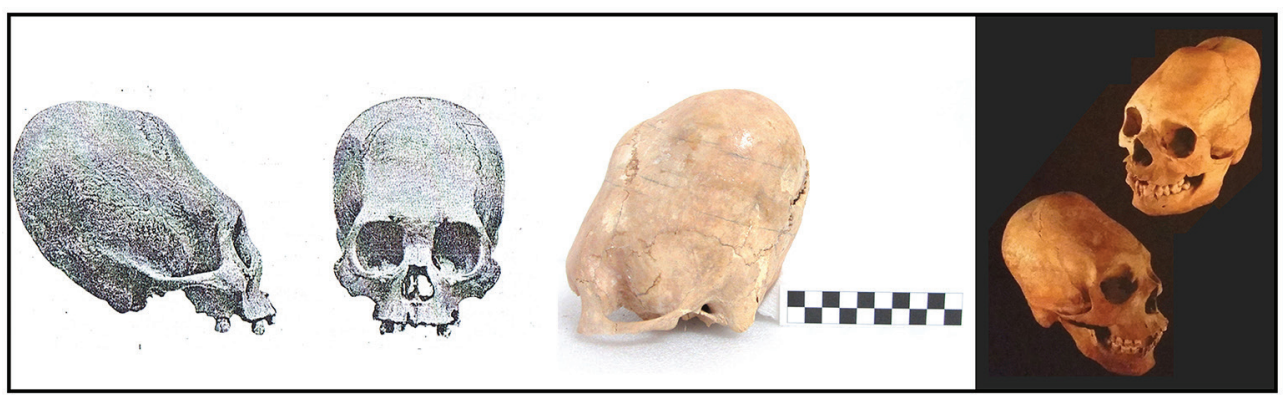

Figura 6. Cráneos con deformación circular. Izquierda: Cráneo recuperado en la Isla de Tilcara (MT N ${ }^{\circ}$ 3876). Centro: cráneo recuperado en la Tumba 2 del Recinto V de Keta Kara (Pelissero 1995). Derecha: Cráneo de la región de Chuquisaca Bolivia (Museo de Charcas, Sucre)

Período 4: 1400-1536 d.C.

Desde inicios del siglo XV, el impacto que generó la ocupación incaica en la región modificó una vez más las condiciones de vida de los pobladores, tanto en la materialidad como en los rasgos arquitectónicos, la alfarería y el paisaje en su totalidad. Durante este período se evidencia el abandono de los semiconglomerados, mientras que probablemente se mantuvieron ocupados algunos sitios en terrazas, conservando las características originales de emplazamiento. Una particularidad de este período es la concentración poblacional en grandes conglomerados que ya se encuentran consolidados, sumado a la incorporación de estrategias y modos de vida propios del Tahuantinsuyo. La relación con los grupos locales se encuentra documentada a partir del surgimiento de espacios especializados para la producción artesanal, explotación agrícola, minera, entre otros, así como también cambios en la ritualidad.

La organización de las poblaciones locales y la sacralidad de los paisajes del sector central de la Quebrada de Humahuaca permiten estimar una fuerte presencia estatal que llevó a integrar esta región como Wamani o provincia incaica.

Además de las evidencias reconocidas en conglomerados, también se identifican en el paisaje otros elementos que, aunque no fueron datados por radiocarbono, marcan la presencia Inca en la región: el asentamiento defensivo del Peñón de la Huerta (Ochoa 2012) y aproximadamente quince tambos asociados a las principales rutas de conexión de la Quebrada con otros ambientes (Ochoa y Otero 2017, 2020; Otero et al. 2018).

Asimismo, el rol protagónico del Pucará de Tilcara debió sostenerse con la articulación con otros centros y en la conexión con grandes ámbitos agrícolas próximos a este poblado, como El Alfarcito, Ovejería y Churquiaguada. A su vez, se ampliarían otras áreas de cultivo en directa 
articulación con La Huerta, entre ellas El Churcal, Sixilera y los campos en la zona del Molulo, todos con una importante complejidad en sus sistemas de regadío (Ochoa y Otero 2017).

Postulamos que esta matriz productiva, inserta en una estructura política con una marcada impronta religiosa, contempló la intervención estatal directa para la apropiación y control de las fuerzas y medios de producción. La regulación de la producción artesanal de bienes suntuarios de fina calidad, alto valor simbólico y, posiblemente, uso selecto (como pudo ser el caso de los objetos de alabastro o los confeccionados en finos metales) demuestran una planificación económica de impacto social en las comunidades locales, con la consecuente readecuación de las prácticas productivas tradicionales (Otero et al. 2018).

Los diagramas de circulación de los recursos, que abarcan más de $220 \mathrm{~km}$ de caminos, de los cuales muchos cuentan con características típicas del Qhapaq Ñan asociados, a su vez, a centros religiosos de altura demuestran la resignificación de las prácticas religiosas locales bajo el culto estatal y la readecuación del sistema vial en función de los intereses del Inca (Ochoa 2019; Ochoa y Otero 2020). Tal es así que la procedencia de las materias primas, particularmente de los minerales y rocas marmóreas y silíceas, presentes en fuentes localizadas en la Puna dan cuenta de que el traslado de insumos para proveer los talleres del Pucará y otros poblados se hizo desde largas distancias.

El conjunto de dataciones obtenidas para este intervalo sugiere una anexión al Imperio más temprana de lo que se consideraba, lo que lleva a reconsiderar también estas formas de intervención estatal tan marcadas, respondiendo quizás a una perduración más extensa de lo previsto en los modelos tradicionales sobre la historia de la expansión Inca.

\section{Período 5: 1536 en adelante}

La contemporaneidad de las luchas que se iniciaron en las esferas de la elite cuzqueña y que generaron el quiebre en la dominación inca convergieron con otro evento que marcó un cambio definitivo para las poblaciones locales: la llegada de los españoles.

De qué modo se dieron los acontecimientos en la región resulta un aspecto problemático desde la información obtenida a partir del contexto arqueológico. Este último se remite a espacios de inhumación entre los que se identifican elementos de origen europeo, de los cuales el cementerio de La Falda, en la planta urbana de Tilcara (Mendonça et al. 2010; Bordach 2006) es uno de los casos más emblemáticos. Entre los objetos que integran el acompañamiento mortuorio se encuentran cuentas de vidrio venecianas, puntas de proyectil de hueso, fragmentos de telas como batista y terciopelo y objetos de hierro (Bordach 2006).

Otra inhumación detectada en proximidad del cementerio de La Falda es el hallazgo referido como familia Gallardo (Otero y y Rivolta 2015). En este caso se trata de un entierro con la estructura típica "en bota" de un individuo femenino en el que se contabilizan diferentes objetos, como cuentas de collar de vidrio de diversos formatos. Si bien las evidencias fueron abordadas desde la materialidad europea registrada en inhumaciones en el interior de los conglomerados, específicamente en los sitios Pucará de Tilcara y La Huerta, claramente el cementerio de La Falda y el hallazgo de familia Gallardo constituyen casos particulares, dado que se encuentran retirados de los grandes poblados.

Podría plantearse para este período que el abandono completo de los sitios se produjo con la creación de los pueblos de indios y su reducción en encomiendas. Otro aspecto a tener en cuenta, y que pudo haber diferenciado a la Quebrada Humahuaca de regiones vecinas, es la tardía ocupación efectiva del territorio por parte de los españoles. Durante las seis décadas en que los habitantes resistieron la conquista, la Quebrada pudo haber funcionado como un espacio natural donde sus características geográficas debieron resultar estratégicas para el refugio de las diferentes 
comunidades indígenas. Asimismo, el tiempo en que se prolongó la ocupación de los sitios por parte de las poblaciones locales no puede ser explicada en profundidad hasta el momento.

\section{A MODO DE REFLEXIÓN}

A lo largo de esta contribución se brindó una secuencia cronológica para el sector central de la Quebrada de Humahuaca con la incorporación de investigaciones actualizadas y nuevos fechados radiocarbónicos, procesados mediante el uso de estadística bayesiana. Pero también se proporcionaron interpretaciones forjadas a partir de la formulación de hipótesis de trabajo entre las que se consideró la presencia de grupos no locales en el espacio quebradeño. Esta hipótesis correspondería a las evidencias y la fase denominada Isla que, lejos de representar al Período Medio tal como lo definieran las cronologías clásicas (González y Pérez 1972), han demostrado ser contemporáneas con los desarrollos locales y extenderse en el tiempo inclusive alcanzando las postrimerías del siglo XIV. Por otra parte, se brindó un panorama acerca de los contenidos particulares que forman parte de cada uno de los grupos y, mediante la noción de continuidad, se elaboró una propuesta explicativa acerca del modo en que las diferentes poblaciones se relacionaron con sus antecesores y predecesores.

La Quebrada de Humahuaca parece haber sido un espacio de convergencia y desplazamiento de grupos en diferentes momentos. De allí que uno de los riesgos en la construcción de secuencias temporales a partir de compartimientos rígidos podría implicar un énfasis a enfocarse exclusivamente en los procesos sociopolíticos locales. Somos conscientes de que armar o construir secuencias cronológicas de fases que demostraron reflejar acontecimientos breves con grados variables de contemporaneidad resultan extremadamente dificultosos dado que expresan prácticas y circunstancias complejas tales como resistencia, dominación, integración, desplazamientos, entre otros. De esta forma entendemos que la formulación de un esquema de cronología cobra sentido en la medida que se ve acompañado de la comprensión de los procesos y de la dinámica regional, por lo que resulta esencial trabajar conjuntamente con eventos previos, transiciones, grados de contemporaneidad, evidencias de carácter local y/o extrarregional, entre otros (figura 7). Asimismo, consideramos que es necesario efectuar ajustes constantes a los modelos cronológicos elaborados en la medida en que las investigaciones generen nuevos conocimientos y permitan acercarnos con mayor precisión a los escenarios que tuvieron lugar en el pasado. Así como también las hipótesis formuladas en esta contribución deberán ser contrastadas a partir de nuevas evidencias que permitan fortalecer o modificar las ideas sugeridas para el sector central de Quebrada de Humahuaca.

\section{AGRADECIMIENTOS}

Agradecemos al personal de las Reservas de los Museos Arqueológico "Dr. E. Casanova" (FFyL-UBA), Etnográfico “J.B.Ambrosetti” (FFyL-UBA) y de Ciencias Naturales de la Universidad de La Plata, por su valiosa colaboración durante la revisión de las colecciones. A los estudiantes de la UBA, UNSa y UNJu y a los técnicos y profesionales del Instituto Interdisciplinario Tilcara por su esforzado trabajo en las tareas de excavación de numerosos sitios arqueológicos. Esta investigación fue financiada por distintos proyectos, entre ellos el de Investigación Científica y Tecnológica (PICT) 2015-2164, Agencia Nacional de Promoción Científica y Tecnológica, "Expresiones de la dominación incaica en el sector central de la Quebrada de Humahuaca (Jujuy, Argentina). Análisis de las materialidades identificadas en Ciénaga Grande y el Pucará de Tilcara”, Programa de Apoyo a la Investigación en el Instituto Interdisciplinario Tilcara (PAITI $\mathrm{N}^{\circ} 2271$ )

"Paisajes Surandinos. Configuraciones del espacio, identidades e interacción prehispánica en el 


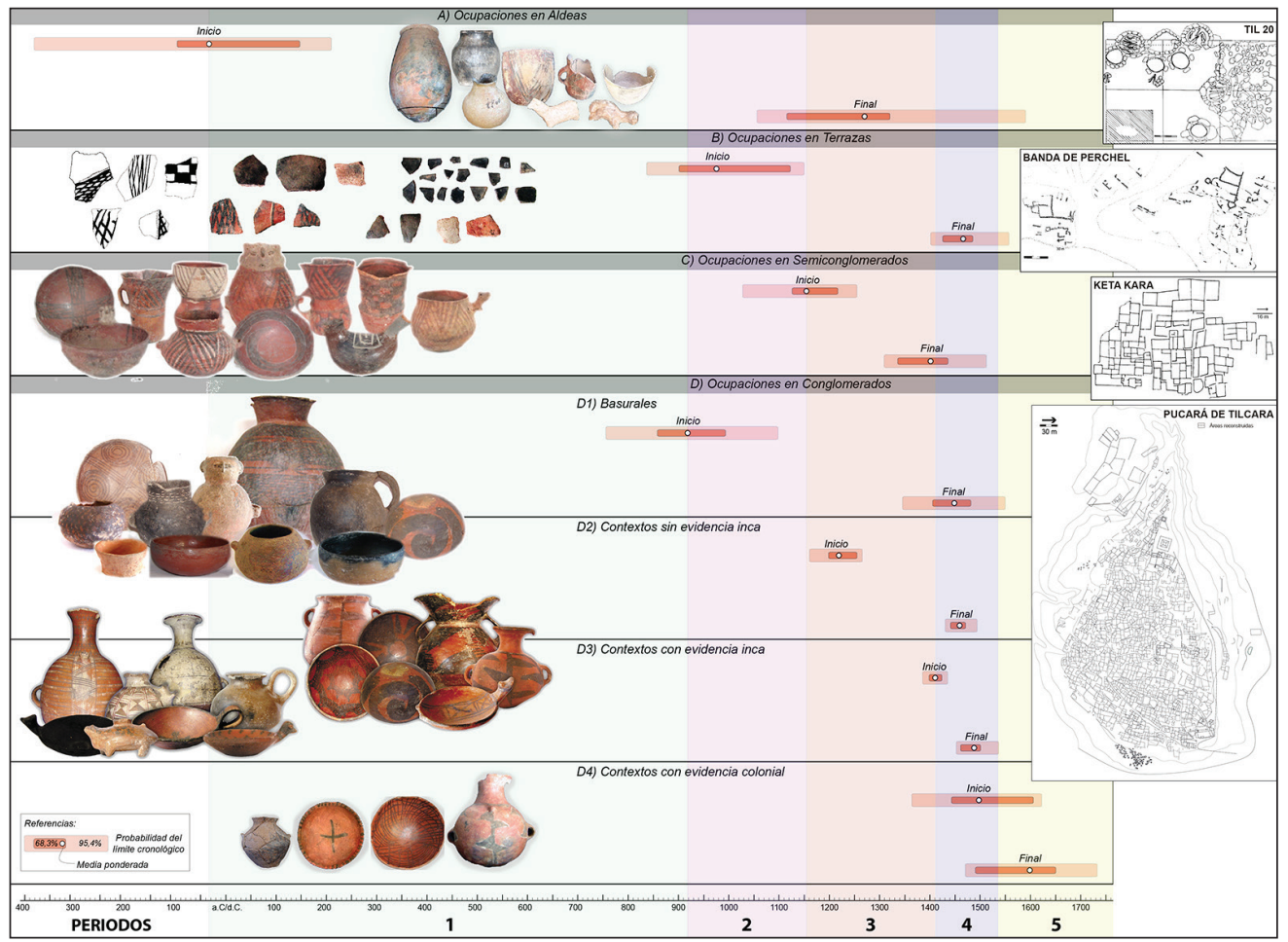

Figura 7. Propuesta de periodificación con ejemplos de conjuntos de piezas cerámicas y planimetrías. a) Planta del conjunto de hallazgos recuperados en Til 20 (tomada de Mendonça et al. 1991). b) Plano de Banda de Perchel, elaborado por Rivolta. c) Planimetría de Keta-Kara, tomado de Raffino (1991) y Pelissero (1995). d) Plano del Pucará de Tilcara, tomado de Otero 2013

Valle Calchaquí Norte y la Quebrada de Humahuaca” e Idea Proyecto de Unidades Ejecutoras, CONICET, "Análisis espacio-temporal de problemáticas socioambientales actuales y emergentes de las eco-regiones de Jujuy. Un enfoque multidisciplinario”.

\section{REFERENCIAS BIBLIOGRÁFICAS}

Aleksandrowicz, S. (1987a). Informe del rescate arqueológico en la Calle Sorpresa (Flia. Arroyo). Informe inédito Instituto Interdisciplinario Tilcara. Ms.

Aleksandrowicz, S. (1987b). Informe de los trabajos realizados en el antigal que suponemos debe ser Puerta de Maidana. Informe Conicet.

Allison, M. J., E. Gerszten, J. Munizaga, C. Santoro y G. Focacci (1981). La práctica de la deformación craneana entre los pueblos andinos precolombinos. Chungara 7: 238-260.

Ambrosetti, J. B. (1908). Exploraciones arqueológicas en la antigua ciudad del Pukará de Tilcara. Manuscrito conservado en el Archivo del Museo Etnográfico. Facultad de Filosofía y Letras, Universidad de Buenos Aires, Buenos Aires. Ms.

Anthony, D.W. (1990). Migration in Archaeology: The Baby and the Bathwater. American Anthropologist, 92: 895-914. 
Arkush, E. (2008). War, Chronology, and Causality in the Titicaca Basin. Latin American Antiquity 19 (4): 339-373.

Arrieta, M.A., L. Bernardi, M. A. Bordach y O. J. Mendonça (2016). Violencia interpersonal en el Noroeste Argentino prehistórico: Expresiones regionales, socioculturales y cronológicas. Estudios Atacameños 53: 75-92.

Barboza, M. C., O. J. Mendonça y M. A. Bordach (2003). Marcadores morfológicos del sexo en un conjunto osteológico del Formativo de Tilcara (Sitio SJ TIL. 20). Revista Argentina de Antropología Biológica 5 (2): 75-88.

Bennett W.C., E. Bleiler y F. Sommer (1948). Northwest Argentine Archaeology. Yale University Publications in Anthropology $\mathrm{N}^{\circ}$ 38, New Haven.

Berberián, E. y A. Nielsen (1998). Sistemas de asentamiento prehispánicos en la etapa Formativa del Valle de Tafí (Pcia. de Tucumán-República Argentina). En E. Berberián(ed.), Sistemas de Asentamiento Prehispánicos en el Valle de Tafi: 21-51. Córdoba. Comechingonia.

Binford, M. W, A. Kolata, M. Brenner, J. Janusek, M. Seddon, M. Abbott y J. Curtis (1997). Climate variation and the rise and fall of Andean civilization. Quaternary Research 47: 235-248.

Blom, D. E. (2005). Embodying borders: human body modification and diversity in Tiwanaku society. Journal of Anthropological Archaeolgy 24: 1-24.

Blom, D. E., B. Hallgrımsson, L. Keng, M. C. Lozada y J. E. Buikstra (1998). Tiwanaku colonization: bioarchaeological implications for migration in the Moquegua valley, Peru. World Archaeology 30: 238-261.

Boman, E. (1908). Antiquités de la région andine de la République Argentine et du désert d'Atacama. Tomos I y II. Paris, Imprimerie Nationale.

Bordach, M. A. (2006). Interacciones étnicas e indicadores de desigualdad social en el Cementerio de La Falda (SJTil 43), Tilcara, Jujuy. Estudios Atacameños 31: 115-128.

Bronk Ramsey, C. (2009). Bayesian analysis of radiocarbon dates. Radiocarbon 51(1): 337-360.

Bronk Ramsey, C. (2017). Methods for summarizing radiocarbon datasets. Radiocarbon 59(6): 1809-1833.

Buck C. E., W. G. Cavanagh y C. D. Litton (1996). Bayesian approach to interpreting archaeological data. Statistics in practice. Willey, Chichester.

Cameron, C. M. (1995). Migration and the Movement of Southwestern Peoples. Journal of Anthropological Archaeology 14: 104-124.

Cameron, C. M. (2013). How people moved among Ancient Societies: Broadening the view. American Anthropologist 115 (2): 218-231.

Carbonari, J., M. I. Baldini, R. Huarte y M. C. Sempé (2011). Seis décadas de dataciones radiocarbónicas de las culturas agroalfareras en el valle de Hualfín, Catamarca, Argentina. En: E. Silvera de Buenader y S. Martínez de Montiel (comps.), El hombre, el medio y sus relaciones: 79-102. Facultad de Ciencias Exactas y Naturales, Universidad Nacional de Catamarca.

Casanova, E. (1934). Notas sobre el Pucará de Huichairas. XXV Congreso Internacional de Americanistas, (II):39-44, La Plata.

Casanova, E. (1937). Contribución al estudio de la Arqueología de La Isla. Relaciones 1: 65-70. 
Relaciones de la Sociedad Argentina de Antropología 46 (2), julio-diciembre 2021: 415-448

Casanova, E. (1942a). El yacimiento arqueológico de Angosto Chico. Relaciones 3: 73-88.

Casanova, E. (1942b). El Pucará de Hornillos. Anales del Instituto de Etnografía Americana de la Universidad Nacional de Cuyo. vol.3: 249-265.

Casanova, E., H. Difrieri, N. Pelissero y J. L. Balbuena (1976). Un corte estratigráfico en el Pucará de Tilcara. Actas y Memorias IV Congreso Nacional de Arqueología Argentina (Primera Parte): 21-32. Revista del Museo de Historia Natural, San Rafael, Mendoza.

Cigliano, E. (1967). Investigaciones antropológicas en el yacimiento de Juella (Dep. Tilcara, Provincia de Jujuy). Revista del Museo de La Plata (Nueva Serie), Tomo VI, Antropología nº 34, La Plata, Buenos Aires.

Cocilovo, J. A., H. H. Varela, M. L. Fuchs (2017a). Divergencia fenotípica y flujo génico en el Área Andina Centro Sur: el trayecto entre Puna de Jujuy, San Pedro de Atacama y Calama. Antropo 37: 1-15.

Cocilovo, J.A., H. H. Varela, S. G. Valdano (2017b). South Central Andean Area. Social Interaction, Relationship and Genetic Divergence in the Atacama Desert. Jorunal of Anthropology and Archaeology 5 (2): 56-73.

Cocilovo, J. A., H. H. Varela, S. G. Valdano (2019). Migración y residencia posmarital en el Noroeste argentino. Relaciones XLIV (2): 233-250.

Debenedetti, S. (1910). Exploración arqueológica de los cementerios prehistóricos de La Isla de Tilcara (Quebrada de Humahuaca, provincia de Jujuy). Publicaciones de la Sección Antropológica $\mathrm{N}^{\circ}$ 6, Facultad de Filosofía y Letras, Buenos Aires.

Debenedetti, S. (1918a). Las ruinas preshipánicas de El Alfarcito (departamento de Tilcara, provincia de Jujuy). Publicaciones de la Sección Antropológica No 18: 3-34.

Debenedetti, S. (1918b). La XIV expedición arqueológica de la Facultad de Filosofía y Letras. Nota preliminar sobre los yacimientos de Perchel, Campo Morado y La Huerta. Facultad de Filosofía y Letras de la UBA. Publicaciones de la Sección Antropológica, $\mathrm{N}^{\circ} 17$, Buenos Aires.

Debenedetti, S. (1930). Las Ruinas del Pucará de Tilcara, Tilcara, Quebrada de Humahuaca (Pcia. De Jujuy). Archivos del Museo Etnográfico II, Primera Parte. Facultad de Filosofía y Letras, Universidad de Buenos Aires.

Delfino, D.; V. Espiro y R. A. Díaz (2015). Prácticas sociales en el pasado y presente de Laguna Blanca (depto. Belén, Catamarca): Reflexiones en torno al modo de vida comunitario agrocéntrico. En: M. A. Korstanje, M. Lazzari, M. Basile, F. Bugliai, V. Lema, L. Pereyra Domingorena y M. Quesada (eds.), Crónicas materiales precolombinas. Arqueología de los primeros poblados del Noroeste argentino: 385-426. Buenos Aires. Sociedad Argentina de Antropología.

Dillenius, J. A. (1913). Craneometría comparativa de los antiguos habitantes de La Isla y del Pukará de Tilcara (provincia de Jujuy). Publicaciones de la Sección Antropología $\mathrm{N}^{\circ}$ 12, Facultad de Filosofía y Letras, Universidad de Buenos Aires.

Engel, Z., G. Skrzypek, T. Chuman, Sefrna L. y M. Mihaljevic (2014). Climate in the western Cordillera of the Central Andes over the last 4300 years. Quaternary Science Review 99: 60-77.

Fernández do Río, S. (2009). Apropiación incaica de un lugar sagrado en la Quebrada de Humahuaca, Jujuy, Argentina. Arqueología 15: 41-62.

Goldstein, P. S. (2015). Multiethnicity, pluralism, and migration in the south central Andes: An alternate path to state expansion. PNAS, 112 (30) 9202-9209. 
González, A.R. (1955). Contextos culturales y cronología en el Área Central del N.O. argentino. Anales de Arqueología y Etnología, vol. XI. Mendoza.

González, A. R, y J. A. Pérez (1972). Argentina indígena, vísperas de la conquista. Buenos Aires, Editorial Paidós.

Greco, C. y C. Otero (2016). Chronology of settlements with pre-Inca and Inca occupations superimposed. The case of Pucará de Tilcara (Humahuaca Gorge, Argentina). Archaeometry 58 (5): 848-862.

Hogg, A. G., T. J. Heaton, Q. Hua, J. G. Palmer, C. Turney, J. Southon, A. Bayliss, P.G Blackwell, G. Boswijk, C. Bronk Ramsey, C. Pearson, F. Petchey, P. Reimer, R. Reimer y L. Wacker (2020). SHCal20 Southern Hemisphere Calibration, 0-55,000 Years cal BP. Radiocarbon 62 (4): 759-778.

Imbelloni, J. (1932). Sobre un ejemplar mimético de deformación craneana: el cráneo 3876 de La Isla de Tilcara (Jujuy, Argentina). Anales del Museo Nacional de Historia Natural 37:193-208.

Janusek, J. W. (2005). Collapse as Cultural Revolution: power and identity in the Tiwanaku to Pacajes transition. Archaeological Papers of the American Anthropological Association 14: 175-209.

Juarez, V. B., L. Pereyra Domingorena, C. Otero y M. B. Cremonte (2020). Una aproximación a la alfarería de las comunidades aldeanas del final del Período Formativo en Tilcara (Quebrada de Humahuaca). Revista del Museo de Antropología 13 (2): 339-348.

Knudson, K. J. (2008). Tiwanaku influence in the South Central Andes: Strontium Isotope Analysis and Middle Horizon Migration. Latin American Antiquity, 19 (1): 3-23.

Knudson, K. J., T. D. Price, J. E. Buikstra y D. E. Blom (2004). The use of strontium isotope analyses to investigate Tiwanaku migration and mortuary ritual in Bolivia and Peru. Archaeometry 46 (1): 5-18.

Kolata, A. L. y C. R. Ortloff (2003). Agroecological Perspectives on the Decline of the Tiwanaku State. En: A. K. Kolata (ed.), Tiwanaku and Its Hinterland: Archaeology and Paleoecology of an Andean Civilization: 181-202. Smithsonian Institution Press.

Krapovickas, P. (1958-59). Un taller de lapidario en el Pucará de Tilcara. Runa 9: 137-151.

Krapovickas, P. (1969). La Instalación aborigen en "Pucará de Yacoraite" (Prov. Jujuy, Rep. Argentina). Etnía 10: 8-12.

Krapovickas, P. (1981-82). Hallazgos incaicos en Tilcara y Yacoraite (Una reinterpretación). Relaciones XIV (2): 67-80.

Lafón, C. R. (1954). Arqueología de la Quebrada de La Huerta (Quebrada de Humahuaca, Provincia de Jujuy). Publicaciones del Instituto de Arqueología I. Instituto de Arqueología, Facultad de Filosofía y Letras, UBA.

Leibowicz, I. (2013). Testimonios de un adiós. Rituales y abandono en Juella ante la conquista Inka de Humahuaca. Arqueología 19 (1): 153-176.

Madrazo, G. (1968). Alfarería prehumahuaca en Tilcara (Quebrada de Humahuaca, Prov. de Jujuy). Etnía 8: $16-18$.

Madrazo, G. (1969a). Reapertura de la investigación en Alfarcito (Pcia. de Jujuy, República Argentina). Monografías del Museo Etnográfico Municipal D. Arce, nº 4, Olavarría.

Madrazo, G. (1969b). Los sectores de edificación en el "Pucará" de Tilcara (Prov. de Jujuy). Etnía 9: 21-27. 
Relaciones de la Sociedad Argentina de Antropología 46 (2), julio-diciembre 2021: 415-448

Madrazo, G. B. y M. Otonello (1966). Tipos de instalación prehispánica en la región de la Puna y su borde. Monografías 1. Museo Etnográfico Municipal “Dámaso Arce”, Olavarría.

Marengo, C. (1954). El Antigal de los Amarillos (Quebrada de Yacoraite, Pcia. de Jujuy). Publicaciones del Instituto de Arqueología II. Instituto de Arqueología, Facultad de Filosofía y Letras, UBA.

Marsh, E. J., M. C. Bruno, S. C. Fritz, P. Baker, J. M. Capriles y C. A. Hastorf (2018). IntCal, SHCal, or a Mixed Curve? Choosing a ${ }^{14} \mathrm{C}$ Calibration Curve for Archaeological and Paleoenvironmental Records from Tropical South America. Radiocarbon 60: 925-940.

Mendonça O. J., M. A. Bordach, M. G. Ammann y M. A. Arrieta (2010). El comportamiento mortuorio en Til 43 y RCh 21 del Tardío al Hispano-indígena: Continuidades, transformaciones y rupturas materiales y simbólicas. Perspectiva regional. Revista Pacarina. Facultad de Humanidades y Ciencias Sociales, Universidad Nacional de Jujuy.

Mendonça O. J., M.A. Bordach, M. V. Grosso y L. B. Dalerba (2002). Ambiente, comunidad y comportamiento biosocial en el Formativo de Tilcara, Quebrada de Humahuaca, Jujuy. Revista Pacarina, II (2): 135-147. Facultad de Humanidades y Ciencias Sociales, Universidad Nacional de Jujuy.

Mendonça O, Bordach A, Ruiz M y M.B. Cremonte (1991). Nuevas evidencias del Período Agroalfarero Temprano en Quebrada de Humahuaca: Los hallazgos del sitio Til.20 (Tilcara, Jujuy). Comechingonia 7: 29-48.

Mercolli, P. H., M. M. Vázquez y K. Menacho (2014). Pucará de Huichairas en el contexto regional de la Quebrada de Humahuaca (departamento de Tilcara, provincia de Jujuy). En: G. Cassiodoro, A. Ré y D. Rindel (eds.), Integración de diferentes niveles de evidencia en la Arqueología Argentina: 1-18. Buenos Aires. Aspha.

Nesbitt, J., B. Ibarra Asencios y F. Tokanai (2020). The Architecture and Chronology of Reparin, Eastern Ancash, Peru. Nawpa Pacha 40 (1): 41-59. DOI: 10.1080/00776297.2019.1666535

Nielsen, A.E. (1996). Demografía y cambio social en Quebrada de Humahuaca (Jujuy, Argentina) 750-1535 d.C. Relaciones de la Sociedad Argentina de Antropología XXI, pp. 307- 354.

Nielsen, A. E. (1997). Tiempo y Cultura Material en la Quebrada de Humahuaca 700-1650 d.C. Serie Monografías. Instituto Interdisciplinario Tilcara, Facultad de Filosofía y Letras, UBA.

Nielsen, A. E. (2001). Evolución social en Quebrada de Humahuaca (AD 700-1536). En E. E. Berberián y A. E. Nielsen (eds.), Historia Argentina Prehispánica: 171-264. Córdoba. Editorial Brujas.

Nielsen, A. E. (2006). Plaza para los antepasados: descentralización y poder corporativo en las formaciones políticas preincaicas de los Andes Circumpuneños. Estudios Atacameños 31: 63-89.

Nielsen, A. E. (2007). El Período de Desarrollos Regionales en la Quebrada de Humahuaca: aspectos cronológicos. En V. I. Williams, B. N. Ventura, A. B. M. Callegari y H. D. Yacobaccio (eds.), Sociedades precolombinas surandinas: temporalidad, interacción y dinámica cultural del NOA en el ámbito de los Andes Centro-Sur: 235-247. Buenos Aires. Editorial Buschi.

Nielsen, A. E. y M. C. Rivolta (1997). Asentamientos residenciales de ocupación breve en la quebrada de Humahuaca (Jujuy, Argentina). Chungará 29 (1): 19-33.

Nielsen, A. y W. Walker (1999). Conquista ritual y dominación política en el Tawantinsuyu: El caso de Los Amarillos (Jujuy, Argentina). En A. Zarankin y F. Acuto (eds.) Sed non satiata: Teoría social en la arqueología latinoamericana contemporánea: 153-169. Buenos Aires. Ediciones del Tridente.

Nielsen, A. E., M. M. Vázquez, P. H. Mercolli y V. Seldes (2003-05). Quebrada del Cementerio: Aportes 
al conocimiento del Período Tardío en la Quebrada de Humahuaca. Cuadernos del Instituto Nacional de Antropología y Pensamiento Latinoamericano 20: 237-256.

Ochoa, P. (2012). El Peñón de La Huerta, transformación de un paisaje social. Conflicto y ontrol. Tesis de Licenciatura inédita, Facultad de Filosofía y Letras, Universidad de Buenos Aires.

Ochoa, P. (2017). Arquitectura para la materialización del poder. Aportes a partir del estudio de nuevos sitios identificados en la quebrada de Sixilera (Quebrada de Humahuaca, Argentina). En Mundo de Antes $\mathrm{N}^{\circ}$ 11: 171-194.

Ochoa, P. (2019). Los paisajes rituales del sector central de la Quebrada de Humahuaca (Jujuy, Argentina). Nuevos aportes a partir del estudio del Qhapaq Nan. En Cuadernos del Instituto Nacional de Antropología y Pensamiento Latinoamericano. Series especiales. Vol. 7, $\mathrm{N}^{\circ}$ 1: 33-47.

Ochoa, P. A. y C. Otero (2020). Usos productivos y rituales de las rutas incaicas del sector central de la Quebrada de Humahuaca (Jujuy, Argentina). Chungara 52 (3): 427-444.

Oliszewski, N. (2017). Las Aldeas "Patrón Tafî" del sur de cumbres Calchaquíes y norte del sistema del Aconquija. Comechingonia, Revista de Arqueología, 21 (1): 205-232.

Olivera, D. E. y J. R. Palma (1997). Cronología y registro arqueológico en el Formativo Temprano en la región de Humahuaca. Avances en Arqueología 3: 77-99.

Otero, C. (2015). Distribución y consumo de cerámica inca en el Pucará de Tilcara (Quebrada de Humahuaca, Argentina). Chungara. Revista de Antropología Chilena $\mathrm{N}^{\circ}$ 47: 401-414.

Otero, C. (2017). Ceramics styles from Pucara de Tilcara settlement during inca domination. En A. Scaro, C. Otero y M. B. Cremonte (eds.), Pre-inca and inca pottery. Quebrada de Humahuaca, Argentina: 107-138. The Latin American Studies Book Series, Cham. Springer.

Otero, C.; Akmentins, S. M. y S. A. Quinteros (2021a). Animales en acción: usos rituales de fauna silvestre y de representaciones zoomorfas en contextos incaicos del Pucará de Tilcara (Quebrada de Humahuaca, Argentina). Estudios Atacameños. Arqueología y antropología surandinas 2021; 67: e3926.

Otero, C.; N. Centeno, M. L. Fuchs, M. S. Gheggi, V. Seldes y K. J. Knudson (2021b). Comportamiento mortuorio durante la caída del Imperio Inca en el Pucará de Tilcara (Quebrada de Humahuaca, Jujuy). Aportes desde la entomología forense y la bioantropología. Latin American Antiquity. En prensa.

Otero, C., M. B. Cremonte y P. A. Ochoa (2018). La construcción del poder incaico en la Quebrada de Humahuaca (Jujuy, Argentina). En M. de los Á. Muñoz (ed.). Interpretando Huellas: Arqueología, Etnohistoria y Etnografía de los Andes y sus Tierras Bajas: 227-245. Instituto de Investigaciones Antropológicas y Museo Arqueológico, Universidad Mayor de San Simón. Cochabamba. Grupo Editorial Kipus.

Otero C. y M. C. Rivolta (2015). Nuevas interpretaciones para la secuencia de ocupación de Tilcara (Quebrada de Humahuaca, Jujuy). Intersecciones en Antropología 16: 145-159.

Otero, C. y M. N. Tarragó (2017). Reconstructing Inca socioeconomic organization through biography analyses of residential houses and workshops of Pucara de Tilcara (Quebrada de Humahuaca, Argentine). Journal of Anthropology and Archaeology 5 (1): 55-72.

Otero y Ochoa (2011). Primeras aproximaciones a la materialización del tiempo y las prácticas productivas especializadas en Tilcara (Quebrada de Humahuaca, Jujuy). Estudios Sociales del NOA, Nueva Serie, 11:121-123. Instituto Interdisciplinario Tilcara, Facultad de Filosofía y Letras, Universidad de Buenos Aires. 
Relaciones de la Sociedad Argentina de Antropología 46 (2), julio-diciembre 2021: 415-448

Ottonello, M. M. y A. Lorandi (1987). Introducción a la Arqueología y Etnología. Diez Mil años de Historia Argentina. Manuales Eudeba, Buenos Aires.

Owen, B. D. (2005). Distant colonies and Explosive Collapse: the two stages of the Tiwanaku diaspora in the Osmore drainage. Latin American Antiquity 16 (1): 45-80.

Owen, B. D. y P. Goldstein (2001). Huari y Tiwanaku: Modelos vs. Evidencias. Boletín de Arqueología PUCP 5: 169-188.

Palma, J. (1998). Curacas y Señores. Una visión de la sociedad política prehispánica en la Quebrada de Humahuaca. Instituto Interdisciplinario Tilcara, Facultad de Filosofía y Letras, Universidad de Buenos Aires.

Palma, J. (2003). La funebria de Campo Morado, Quebrada de Humahuaca (Depto. de Tilcara, Pcia. De Jujuy). Relaciones XXXVIII: 61-74.

Palma, J. y D. Olivera (1992-93). Hacia la contrastación de un modelo arqueológico para el Formativo Regional en Humahuaca: El caso de Estancia Grande. Cuadernos del Instituto de Antropología y Pensamiento Latinoamericano 14: 237-259.

Palma, J.; S. Fernández do Río; M. A. Runcio y L. Capizzi (2006). Control Imperial Inka en Campo Morado (Quebrada de Humahuaca, Provincia de Jujuy). Runa XXVI: 165-182.

Pelissero N. (1969). Arqueología de la Quebrada de Juella. Su integración en la Cultura Humahuaca. Jujuy. Dirección Provincial de Cultura.

Pelissero N. (1995). El sitio arqueológico de Keta-Kara en el sistema cultural de la ceja de Puna, Dpto. de Tilcara, Pcia. de Jujuy. Buenos Aires. Colección Mankacén, CAEA.

Raffino, R. (1991). Poblaciones Indígenas en Argentina. Urbanismo y Proceso Social Precolombino Buenos Aires. Tipográfica Editora.

Raffino, R. y R. Alvis (1993). Las ciudades Inka en Argentina Arqueología de La Huerta de Humahuaca. En: R. Raffino (ed.), Inka Arqueología, Historia y Urbanismo del Altiplano Andino:.37-76. Buenos Aires. Corregidor.

Reimer, P. J, W. E. N. Austin, E. Bard, A. Bayliss, P. G. Blackwell, C. Bronk Ramsey, M. Butzin, H. Cheng, R. L. Edwards, M. Friedrich, P. M. Grootes, T. P. Guilderson, I. Hajdas, T. J. Heaton, A. G. Hogg, K. A. Hughen, B. Kromer, S. W. Manning, R. Muscheler, J. G. Palmer, C. Pearson, J. van der Plicht, R. W. Reimer, D. A. Richards, E. M. Scott, J. R. Southon, C. S. M. Turney, L. Wacker, F. Adolphi, U. Büntgen, M. Capano, S. M. Fahrni, A. Fogtmann-Schulz, R. Friedrich, P. Köhler, S. Kudsk, F. Miyake, J. Olsen, F. Reinig, M. Sakamoto, A. Sookdeo y S. Tálamo (2020). The IntCal20 Northern Hemisphere Radiocarbon Age Calibration Curve (0-55 cal kBP). Radiocarbon 62: 725-757.

Rivelli F. R. y A. L. Zelarayan (2016). Relieve, morfogénesis, ordenamiento territorial y riesgos. El caso de Tilcara (Jujuy, República Argentina). Actas Científicas Congreso Internacional de Geografía- $77^{\circ}$ Semana de Geografía: 207-224. San Miguel de Tucumán.

Rivolta, M. C. (1996a). Calle Lavalle y Sorpresa: Aportes a la Investigación Arqueológica de la Quebrada de Humahuaca. XXVAniversario Museo Arqueológico Dr. Eduardo Casanova: 129-135. Instituto Interdisciplinario Tilcara, Facultad de Filosofía y Letras, UBA.

Rivolta, M. C. (1996b). Quebrada de Sarahuaico: Nuevas Perspectivas (Dpto. Tilcara, Pcia. de Jujuy). Actas del IX Congreso Nacional de Arqueología Argentina, $13^{\circ}$ parte: 253-263, San Rafael, Mendoza. 
Rivolta, M. C. (1997). Terrazas domésticas: un caso de estudio en la Quebrada de Humahuaca, Provincia de Jujuy. Estudios Sociales del NOA, 1 (1): 59-79.

Rivolta, M. C. (2000). 90 años de investigación en la Quebrada de Humahuaca: un estudio reflexivo. Serie Monográfica 5, Instituto Interdisciplinario Tilcara, Facultad de Filosofía y Letras, UBA.

Rivolta, M. C. (2003a). Aportes a la arqueología de Tilcara (pcia. de Jujuy) en relación a observaciones efectuadas por Eric Boman. Pacarina 3: 287-295.

Rivolta, M. C. (2003b). Los Sitios en Terrazas Domésticas como parte de la Dinámica Social en la Quebrada de Humahuaca (Provincia de Jujuy). Tesis de Doctorado inédita, Facultad de Filosofía y Letras, Universidad de Buenos Aires.

Rivolta, M. C. (2004). La arquitectura como indicador de ocupación durante los Desarrollos Regionales en Quebrada de Humahuaca. Actas del XV Congreso Nacional de Arqueología Argentina, Universidad Nacional de Río Cuarto.

Rivolta M. C. y M. E. Albeck (1992). Los asentamientos tempranos en la Localidad de Tilcara: S. Juj.Til.22, Provincia de Jujuy. Cuadernos 3: 86-93.

Rivolta, M. C.; C. Otero y C. Greco (2017). Reconsidering Isla Occupation. Pottery, chronology and settlement. En A. Scaro, C. Otero y M. B. Cremonte (eds.). Pre-Inca and Inca Pottery. Quebrada de Humahuaca, Argentina: 29-50, Springer.

Rivolta, M. C.; C. Otero y V. Seldes (2010b). Actualización de la Problemática del sitio Angosto Chico (Jujuy, Argentina). Arqueología 16: 87-103.

Rivolta, M. C., V. Seldes y P. Mercolli (2010a). Ocupaciones Tempranas en sectores Urbanos de la localidad de Tilcara (Jujuy, Argentina). Actas del XVII Congreso Nacional de Arqueología Chilena, Actas 1: 155-163, Valdivia.

Salas, A. (1948). Un Nuevo Yacimiento Arqueológico en la Región Humahuaca. Actes du XXVIII Congres International des Américanistes: 643-647.

Sancho, C., J. L. Peña, F. Rivelli, E. Rhodes y A. Muñoz (2008). Geomorpholigical evolution of the Tilcara alluvial fan (Jujuy Province, NW Argentina): Tectonic implications and paleoenvironmental considerations. Journal of South American Science 26: 68-77.

Scaro, A. y G. Sica (2015). El Pucará de Perchel (dpto. Tilcara, Jujuy, Argentina): un lugar estratégico en el sector central de la Quebrada de Humahuaca. Arqueología 21(1): 31-45.

Schuel, K. (1930). Ruinas de las poblaciones indígenas de la provincia de Jujuy. VReunión SociedadArgentina de Patología Regional del Norte Argentino: 1430-1451. Buenos Aires.

Seldes, V. (2006). Bioarqueología de poblaciones prehistóricas de la Quebrada de Humahuaca (Jujuy, Argentina). Estudios Atacameños 31: 47-61.

Sharratt, N. (2016). Collapse and cohesion: building community in the aftermath of Tiwanaku state breakdown, World Archaeology 48 (1): 144-163.

Smith S. C. y J. W. Janusek (2014). Political mosaics and networks: Tiwanaku expansion into the upper Desaguadero Valley, Bolivia. World Archaeology 46 (5): 681-704.

Stanish, C. (2003). Ancient Tititcaca. The Evolution of Complex Society in Southern Peru and Northern Bolivia. University of California Press. 
Relaciones de la Sociedad Argentina de Antropología 46 (2), julio-diciembre 2021: 415-448

Taboada, C. y C. Angiorama (2003). Posibilidades de un enfoque dinámico para el estudio de la arquitectura doméstica prehispánica. Un caso de aplicación en Los Amarillos (Jujuy). Relaciones XXVIII: 101-115.

Tarragó, M. N. (1992). Áreas de actividad y formación del sitio de Tilcara. Cuadernos 3: 64-74.

Tarragó, M. N. (2000). Chacras y pukara. Desarrollos sociales Tardíos. Nueva Historia Argentina. Los Pueblos Originarios y la Conquista, Tomo I: 257-300. Editorial Sudamericana.

Tarragó M. N. y M. E. Albeck (1997). Fechados Radiocarbónicos para el Sector Medio de la Quebrada de Humahuaca. Avances en Arqueología 3: 101-116.

Trauth, M. H., R. A. Alonso, K. R. Haselton, R. L. Hermanns y M. R. Strecker (2000=. Climate Change and mass movements in the NW Argentine Andes. Earth and Planetary Science Letters, 179: 243-256.

Zaburlín, M. A., H. E. Mamaní, S. Dip y M. E. Albeck (1996). SJujTil-41: Alfarcito. Variaciones sobre un clásico. Actas y Memorias del XI Congreso Nacional de Arqueología Argentina, Tomo XXV (1/4): 71-86, Revista del Museo de Historia Natural de San Rafael, Mendoza. 